\title{
Intensification of the Global Water Cycle and Evidence from Ocean Salinity: A Synthesis Review
}

\author{
Lisan $\mathrm{Yu}^{1 *}$, Simon A. Josey ${ }^{2}$, Fred Bingham ${ }^{3}$, and Tony Lee ${ }^{4}$ \\ ${ }^{1}$ Department of Physical Oceanography, Woods Hole Oceanographic Institution, \\ Woods Hole, MA, USA \\ 2 National Oceanography Centre, Southampton, United Kingdom \\ ${ }^{3}$ Center for Marine Science, University of North Carolina Wilmington, Wilmington, NC, USA \\ ${ }^{4}$ Jet Propulsion Laboratory, California Institute of Technology, Pasadena, CA, USA \\ ${ }^{*}$ Corresponding contact information: Dr. Lisan Yu, Department of Physical Oceanography, \\ Woods Hole Oceanographic Institution, MS\#21, Woods Hole, MA 02543, USA. Email: \\ lyu@whoi.edu
}

Short title: Ocean Salinity and the Global Water Cycle

Keywords: global water cycle; ocean salinity; surface freshwater flux; evaporation; precipitation; long-term trends. 


\title{
Main Text
}

\begin{abstract}
( $<200$ words $)$
The ocean plays a dominant role in the global water cycle. It is the center of action for global evaporation and precipitation, and the remote moisture supplier of continental precipitation. It also acts to some extent as Nature's rain gauge as it tells us about the long-term changes in the global water cycle through monitoring the changes in ocean surface salinity. As climate warms, the global water cycle is expected to intensify as a result of the strong nonlinear dependence of water vapor pressure (moisture holding capacity) on temperature. Such change is of great concern as it has profound socioeconomic impacts throughout the globe. Despite the evidence of an intensified global water cycle, two important questions remain: What is the pattern of the warming-induced intensification of the water cycle? And what is the rate of the intensification? This article provides a synthesis review of recent progress in diagnosing and understanding the changes in both the global water cycle and ocean salinity in recent decades. Targeted numerical ocean model experiments are also reviewed to provide insights into the response of salinity to the changes in evaporation-minus-precipitation flux, meltwater runoff, and ocean warming.
\end{abstract}

\section{Introduction ( $<750$ words)}

The ocean is at the heart of the Earth's global water cycle: it is the source of $86 \%$ of global evaporation and the receiver of $78 \%$ of global precipitation ${ }^{1,2}$. The $8 \%$ imbalance in the freshwater exchange over the ocean surface reflects the fact that it serves as an important, remote source of continental precipitation ${ }^{3,4}$. The water vapor transported from the ocean into the atmosphere and then to the continents influences where and when floods and extreme weather occur on land ${ }^{5,6,7}$. The continental precipitation flows over the ground as surface runoff, some of which eventually reenters the ocean. This surface runoff together with meltwater runoff from snow and ice reestablishes the balance of the freshwater budget in the ocean.

The cycling of freshwater between evaporation $(E)$, precipitation $(P)$, and runoff $(R)$ leaves a strong imprint on ocean salinity ${ }^{8,9} . P$ and $R$ bring freshwater into the ocean, diluting the salt content of the surface water. $E$ from the ocean's surface leaves salt behind, increasing salinity. The exchange of the freshwater between the atmosphere and ocean acts in concert with ocean circulation and mixing, raising the sensitivity of the salinity distribution to the balance between $E, P$, and $R$. On a time-mean basis, surface waters of high salinity are generally located in the subtropical regions where $E$ exceeds $P$, and surface waters of low salinity are located in the tropical and high-latitude regions where $P$ and/or $R$ exceeds $E$ (Figures 1a-b). Thus, ocean surface salinity integrates the complex multifactorial variations in the water cycle, acting to some extent as Nature's rain gauge ${ }^{10,11}$.

Growing evidence indicates that the global water cycle ${ }^{12,13}$ has responded to the climate warming in the past half century ${ }^{3,14-16}$, demonstrated by an increase in global atmospheric moisture content ${ }^{17}$, the frequency of heavy rain events ${ }^{18,19}$, evaporation ${ }^{20}$ and evapotranspiration ${ }^{21}$. Ocean salinity observations support this intensification, showing that surface salty waters have become saltier in the subtropical oceans and surface fresh waters fresher in the tropical rain belt ${ }^{22-26}$. Despite the 
strong evidence, two of the most important questions remain: What is the pattern of the warming-induced intensification of the water cycle? And what is the rate of the intensification?

Accurate quantification of the changes in $E$ and $P$ is central to addressing these questions, but these water cycle components are notoriously difficult to observe. $E$ cannot be directly remotely sensed as it cannot be detected by electromagnetic radiation. The commonly used bulk parameterization, which computes $E$ from near-surface meteorological variables and SST obtained either from observations or model outputs ${ }^{27,28}$, has a large uncertainty ${ }^{29} . P$ has long been inferred from visible-infrared and passive microwave retrievals ${ }^{30}$. The launch of the Global Precipitation Measurement (GPM) mission in 2014 has significantly improved global observations of $P^{31}$. Still, the potential of ocean surface salinity as a rain gauge to provide an alternative measure of changing rainfall and evaporation is thus appealing. The trends in ocean surface salinity appear to hold important insights into the long-term variations of the water cycle and the effects of climate change.

This article provides a synthesis review of recent progress in diagnosing and understanding the changes in both the global water cycle and ocean surface salinity. Targeted numerical ocean model experiments are reviewed to provide some insights into the response of salinity to changes in $E-P$, meltwater runoff, and ocean warming. However, the effect of surface runoff owing to freshwater discharge from global rivers is not included. River input impacts the ocean locally ${ }^{32}$ but has a limited contribution to the ocean's overall freshwater budget ${ }^{33,34}$. It is expected that our knowledge of global surface runoffs and their interactions with coastal and open oceans will be significantly advanced with the planned launch of the Surface Water and Ocean Topography (SWOT) Mission ${ }^{35}$ in 2021.

\section{Data and Methods}

This review includes data analysis and ocean model simulations. Data analysis focuses on the changes in ocean water cycle and salinity occurring in the past three decades spanning from 1988 to 2017. The period is marked by the availability of increased and improved satellite observations. In particular, the passive microwave (PMW) observations from the series of Special Sensor Microwave Imager (SSM/I) and the Special Sensor Microwave Imager Sounder (SSMIS) devices onboard Defense Meteorological Satellite Program (DMSP) satellites ${ }^{36}$ has allowed, for the first time, the retrieval of surface meteorological variables that are needed for the parameterization-based computation of $E^{28}$. PMW observations are also superior to previously used visible-infrared observations for estimating instantaneous precipitation, resulting in improved spatial and temporal variability of satellite-based $P$ products ${ }^{37}$. Reanalyses of the global atmosphere using data-assimilating models have shown marked improvements when PMW observations are included ${ }^{38-40}$.

Four sets of $E-P$ fields are used here to construct a synthesized view of the past changes in the ocean water cycle by consolidating common patterns among the products. One is a combined product, using $E$ from the second-generation Objectively Analyzed air-sea Fluxes (OAFlux2) products on $0.25^{\circ}$ resolution ${ }^{41}$ and $P$ from the Global Precipitation Climatology Project $(\text { GPCP })^{30}$. The other three products are from the latest atmospheric reanalyses: the fifth 
generation of atmospheric reanalysis from the European Centre for Medium-Range Weather Forecasts (ERA5) ${ }^{42}$, the Japanese 55-year Reanalysis (JRA55) ${ }^{43}$, and the Modern-Era Retrospective analysis for Research and Applications, Version 2 (MERRA-2) ${ }^{44}$.

Historical in situ salinity and temperature observations are spatiotemporally inhomogeneous ${ }^{45}$. Long-term changes of sea-surface salinity (SSS) have been estimated using both linear trend analysis ${ }^{22,23,25,46,47}$ and mean differences between the Argo era (2003-present) and historical ocean climatologies ${ }^{48,49}$. Two monthly gridded objective analyses have also been constructed from historical archives of subsurface ocean temperature and salinity profiles. They are the Ishii dataset ${ }^{50}$ and the version 4 of the Met Office Hadley Centre "EN" dataset (EN4) ${ }^{51}$. Droghei et al. 52 suggested that datasets constructed from in situ observations may be sufficient for studies on the large scales $(\sim 1,000 \mathrm{~km})$ and at low temporal resolution $(\sim$ seasonally).

Diagnosis of the long-term changes in the water cycle and salinity is based on linear trends in the annual mean fields. These trends were estimated as linear fits against time and then multiplied by the 30-year analysis period (1988-2017) to show the total change. To determine the statistical significance of the trends, a student's $t$-test was performed with an overall two-tailed confidence interval of $90 \%$. Climate varies over all spatial and temporal scales from the diurnal to interannual to multi-decadal and millennial. Detecting long-term changes in mean conditions requires long-term averages to overcome the effects of natural variability (climate noise). It is recommended by the World Meteorological Organization that a minimum duration of 30 years is necessary for determining the statistical properties of climate change. The 30 -year analysis period in this review meets this minimum requirement.

\section{Results}

\section{Mean $E-P$ and its predicted changes}

The spatial distribution of net $E-P$ flux (Figure la) captures the essence of the water cycle operation over the ocean: the variation of $E-P$ with latitudes is a result of the atmospheric transport and condensation of water vapor evaporated from the ocean. The most evaporative regions of the global ocean are in the subtropics, where dry, subsiding air of the subtropical highpressure centers feeds the trade winds that induce strong evaporation and low precipitation $(E>$ $P)$. The wettest regions on the planet are in the deep tropics, where the trade-wind convergence forces the water-laden air to rise in altitude, forming clouds and falling as rain in the Intertropical Convergence Zone (ITCZ) between the equator and $10^{\circ} \mathrm{N}$ in all the ocean basins and the South Pacific Convergence Zone (SPCZ) in the western South Pacific. The higher latitudes (poleward of $45^{\circ}$ north and south) are also net precipitation zones $(P>E)$, where atmospheric moisture convergence is supplied by mid-latitude storm systems and fronts. In general, the patterns of $E-P$ are strongly zonal, except for the North Indian Ocean, where $E$ dominates in the Arabian Sea and $P$ dominates in the Bay of Bengal and to a lesser extent in the South Pacific.

The mean $E-P$ pattern is expected to intensify in a warming climate according to the ClausiusClapeyron (CC) relation ${ }^{12}$. Under constant relative humidity, the $\mathrm{CC}$ relation states that 
saturation water vapor pressure (the water holding capacity of the air) increases at a rate of approximately $7 \%$ per degree Celsius of warming (hereafter $7 \%{ }^{\circ} \mathrm{C}^{-1}$ ). This rate of increase in atmospheric moisture content has been confirmed during the past few decades ${ }^{17,53}$. Since precipitation and evaporation are tightly linked to the vapor pressure of water, it is predicted that the dry subtropical regions of net evaporation will become drier and the wet tropical and higher latitudes of net precipitation will become wetter ${ }^{13}$. This "dry gets drier and wet gets wetter" (DDWW) paradigm can be derived from the following atmospheric moisture budget equation ${ }^{54}$.

$$
\frac{\partial w}{\partial t}+\nabla \cdot \frac{1}{g} \int_{0}^{p_{s}} v q d p=E-P
$$

where $w=\frac{1}{g} \int_{0}^{p_{s}} q d p$ is the integrated precipitable water within the troposphere, $q$ the atmospheric specific humidity, $g$ is gravity, and $v$ the horizontal wind vector. The first term on the left-handside represents the change in storage of total moisture and is small on monthly and longer timescales. Hence, long-term changes in surface net $E-P$ flux is determined primarily by the long-term changes in the divergence of the vertically integrated moisture flux. Using $\delta$ to denote the change in each variable induced by the warmer climate, Equation (1) can be expressed as:

$$
\delta(E-P) \approx \nabla \cdot \frac{1}{g} \int_{0}^{p_{s}} \boldsymbol{v} \delta q d p+\nabla \cdot \frac{1}{g} \int_{0}^{p_{s}} \delta \boldsymbol{v} q d p
$$

which states that the two major contributions to $\delta(E-P)$ are changes in the moisture content of the atmosphere (the first term on the right-hand-side (rhs)) and changes in the atmospheric circulation (the second term on the rhs). Assuming that the large-scale atmospheric circulation remains unchanged (i.e., $\delta \boldsymbol{v} \approx 0$ ) and $\delta q$ increases by $\sim 7 \%{ }^{\circ} \mathrm{C}^{-1}$ (i.e., $\delta q \approx q \times 7 \% /{ }^{\circ} \mathrm{C}$ ), Equation (2) yields the following result:

$$
\delta(E-P) \approx \nabla \cdot \frac{1}{g} \int_{0}^{p_{s}} v q \times 7 \% /{ }^{\circ} C d p \approx(E-P) \times 7 \% /{ }^{\circ} C
$$

Equation (3) reveals an important relation: the change in $E-P$ scales with $E-P$, with the scaling coefficient being the $\mathrm{CC}$ rate of approximately $7 \%{ }^{\circ} \mathrm{C}^{-1}$. Accordingly, the pattern of $E-P$ would remain the same, but the magnitude would become more extreme leading to amplification of the differences between dry and wet regions ${ }^{13}$. Climate models show that the enhancement of the mean $E-P$ pattern is a robust feature in anthropogenic forcing simulations. Mean precipitation generally increases in the tropics and extratropics and decreases in the subtropics, and precipitation extremes increase across almost the entire globe ${ }^{13,19,55,56}$. Seager et al. ${ }^{57}$ deemed that the DDWW is essentially a certainty in future changes of the water cycle, as long as relative humidity remains approximately constant. It is generally expected that changes in relative humidity are small on large scales ${ }^{58}$, although locally, there may be some change in relative humidity caused by the changes in large-scale circulation patterns ${ }^{53}$.

Despite the success of the DDWW paradigm in predicting the large-scale hydrological response to climate warming, many studies have articulated the need to extend the DDWW hypothesis to account for a broader range of observed and projected changes in the global water cycle. Of 
particular interest is the assumption that the large-scale atmospheric circulation remains unchanged. Discrepancies exist in using the DDWW paradigm to explain an observed large-scale decline in $P$ in the subtropical dry zones ${ }^{59,60}$. Held and Soden ${ }^{13}$ suggested that the "dry-get-drier" in the subtropics is largely accomplished by a decline in $P$. Thus, all else unchanged, $P$ will be reduced in regions of $P<E$, including the subtropical dry margins of both the tropical rain belt and of the midlatitude storm tracks (Figure 1a). However, most climate model studies have shown that the decline in $P$ is primarily driven by a poleward shift of subsidence associated with the expansion of the Hadley cell ${ }^{61}$ and a poleward shift of the storm tracks ${ }^{62}$. In contrast to the thermodynamic "dry-get-drier" mechanism, this less known dynamical response acts mainly to reduce $P$ on the poleward side of the subtropical $P$ minima, and not on the dry margins of the tropical rain belt ${ }^{60}$. Despite the successful prediction of the subtropical decline in $P$ by both the "dry-get-drier" and poleward expansion mechanisms, the subtropical area affected by the two mechanisms differs owing to the differences in interpreting the role of the large-scale atmospheric circulation.

Discrepancies from the DDWW paradigm also occur in the $E-P$ response in climate models. The rate of change in modeled $E-P$ is generally less than predicted by $\mathrm{CC}$, at around $2 \%{ }^{\circ} \mathrm{C}^{-1}{ }^{12,}, 63-67$, although a rate of total water vapor increase of $7 \%{ }^{\circ} \mathrm{C}^{-1}$ has been confirmed by observations 17,53 , 68. The discrepancy is often explained in terms of the thermodynamic energy constraints on the water cycle, which force changes of global $P$ to accord with the availability of energy flux rather than with changes in temperature ${ }^{12,63,69}$. Broadly, the global-mean $P$ in climate model projections is dominated by three terms of the global energy budget: the radiative cooling at the top of the atmosphere (TOA), the net shortwave and longwave radiative energy flux at the surface, and the surface evaporative energy flux (mostly restricted to the oceans). The limited amount of atmospheric surface forcing that is partitioned into $E$ and the response timescales of the atmosphere in radiating away the latent heat released from the formation of precipitation are the main limiting factors that cap the hydrologic sensitivity to anthropogenic warming at a rate of $2 \%{ }^{\circ} \mathrm{C}^{-1} 67,70,71$.

\section{Estimated changes of $E-P$ and uncertainties}

In the past three decades since 1987, satellite-derived products along with improved atmospheric reanalyses have been significant sources of data for assessing and understanding the operation of the global water cycle in the present climate conditions. During this period, global temperatures have continued to rise. The satellite-derived ocean-surface air temperature (Ta) record obtained by the OAFlux 2 analysis ${ }^{72}$ shows that near-surface air temperature has steadily increased, at a rate of $0.15 \pm 0.03^{\circ} \mathrm{C}$ per decade since the late $1980 \mathrm{~s}$ (Figure 2). At the same time, the average global sea surface temperature (SST) has also increased, at a similar rate of $0.14 \pm 0.03^{\circ} \mathrm{C}$ per decade. Both trends are statistically significant at the $90 \%$ confidence interval based on the student's t-test, and notably match in short-term detail. These trends are consistent with those deduced from the global land and ocean surface temperature dataset constructed by the Goddard Institute for Space Studies (GISS) ${ }^{73,74}$. The GISS dataset shows that the average global temperature on Earth has increased by about $0.8^{\circ} \mathrm{C}$ since 1880 . Two-thirds of the warming has occurred since 1975 , at a rate of roughly $0.15-0.20^{\circ} \mathrm{C}$ per decade. 
Changes of $E$ and $P$ over the global ocean in response to this warming are given by linear trend estimates performed for four different time series and converted to a percentage of change per degree $\mathrm{C}\left(\%{ }^{\circ} \mathrm{C}^{-1}\right)$ (see Figures 3a-d). Despite large year-to-year fluctuations, both $E$ and $P$ are consistent in depicting a rapid intensification of the ocean water cycle in the 1990s but deviate from each other after 2000. Nonetheless, trends during the 30-year period are upward in the four time series shown, and these trends are statistically significant at the $90 \%$ confidence interval except for $P$ from GPCP. The latter has a trend of $2 \pm 3 \%{ }^{\circ} \mathrm{C}^{-1}$, which is non-significant using a Student's t-test.

The three products, OAFlux2, JRA55, and MERRA5, have a similar increase rate for $E$, ranging between $8-9 \%{ }^{\circ} \mathrm{C}^{-1}$ with an uncertainty about $3-4 \%{ }^{\circ} \mathrm{C}^{-1}$. This rate of change is slightly higher than the $\mathrm{CC}$ rate, but within the statistical margin of error. By comparison, ERA5 has an exceptionally large increase in both $E$ and $P$, at a rate of about $18 \pm 3 \%{ }^{\circ} \mathrm{C}^{-1}$, and so does the $P$ in JRA55, at about $14 \pm 3 \%{ }^{\circ} \mathrm{C}^{-1}$. The rate of increase of $P$ in other two products is considerably weaker, at $2 \pm 3 \%{ }^{\circ} \mathrm{C}^{-1}$ for GPCP and $5 \pm 3 \%{ }^{\circ} \mathrm{C}^{-1}$ for MERRA2. The products have a better agreement in the rate of increase for $E$ than for $P$.

Linear trends in the $E-P$ time series reflect a balance of the trends between $E$ and $P$ (Figures $3 \mathrm{e}$ h). Three products, OAFlux2 - GPCP, ERA5, and MERRA2, have positive trends over the 30year period, showing that the ocean water cycle has intensified corresponding to the warming. On the other hand, JRA55 is the only product that has a negative trend, driven by a faster increase of $P$. In the three products where the $E-P$ trend is positive, the rate of increase in $E$ is larger than that of $P$. The rates of change of $E-P$ are not converted to percentage per degree Celsius. The reason is that the conversion needs to use the average global $E-P$ budget as a scaling, but the four products have large differences in budgets, from 13 to $26 \mathrm{~cm} / \mathrm{yr}$, which is a major source of bias for the conversion. As discussed in Schanze et al. ${ }^{34}$ and $\mathrm{Yu}$ et al ${ }^{75}$, satellitebased as well as reanalyzed $E-P$ products have difficulties achieving a balanced budget over the global ocean.

Spatial patterns of $E-P$ in the four products (Figures 4a-d) show that the common features of the changes are the intensification of the ITCZ rainfall in the tropical Atlantic and Pacific as well as in the sub-Antarctic Pacific sector, and the equatorward expansion and intensification of the subtropical dry zone in the South Pacific and South Atlantic. Overall, the trend patterns of OAFlux2 - GPCP are similar to those of ERA5, although the two products disagree with the rate of change in global means. Differences among the four products are large. For instance, there is a weakening of the subtropical $E-P$ maxima in North Atlantic in MERRA, but a strengthening in JRA55 and ERA5. OAFlux2 - GPCP shows barely any change in this region. The trend patterns in JRA55 are dominated by excessively large intensification of the tropical rain band, which explains the negative trend in average global $E-P$.

The better agreement in the decadal changes in $E$ than in $P$ underlies the fact that the two water cycle components are governed by very different dynamical processes. $E$ is a continuous and slow process, while $P$ is highly intermittent, spatially strongly varying, and governed by both large-scale and small-scale processes (such as cumulus convection) ${ }^{2}$. The reanalyzed $P$ are sensitive to the use of different cumulus parameterizations ${ }^{76}$. In addition, the $2.5^{\circ}$ gridded GPCP monthly product is constructed from blending in situ station observations and satellite derived 
information ${ }^{30}$, and has large uncertainty due to the uncertainty in algorithms and also the coarse spatial resolution ${ }^{37}$. Additionally, the temporal coverage of $\sim 30$ years may be too short so that trends are likely affected by natural decadal modes of variability. These difficulties contribute to large deviations in long-term trends of $P$ among products and hinder accurate assessments of the changes of the global water cycle.

\section{Observed amplification of the mean sea-surface salinity}

Long-term changes of sea-surface salinity (SSS) ${ }^{22-25,46-48}$ have been constructed from historical salinity databases by many studies using various approaches. Three studies, Boyer et al. ${ }^{23}$, Durack and Wijffels ${ }^{25}$, and Hosoda et al. ${ }^{48}$, focused particularly on multidecadal trends of nearsurface salinity on a global scale, although they differ in analysis periods and methodologies of processing historical data archives ${ }^{77}$. Despite the differences, the patterns of salinity change from the three studies showed remarkable similarities with the climatological-mean salinity patterns (Figure 5). The long-term SSS trends are negative (surface freshening) in the $P$ dominated regions such as the Indo-Pacific warm and fresh pool and the regions under the ITCZ, and positive (surface salinification) in the $E$ dominated subtropical regions. This amplification of the mean SSS pattern has reinforced the marked contrast between the fresher Pacific and the saltier Atlantic, strengthening the existing gradients of the SSS spatial distribution ${ }^{77}$. The longterm increase of the subtropical SSS maxima and decrease of the tropical SSS minima provide an independent line of evidence demonstrating that the water cycle has responded to climate warming in a way as predicted by the DDWW paradigm ${ }^{12,13}$.

Using the observed salinity trends to fingerprint the amplified water cycle has gained increasing prominence in recent years ${ }^{26,77-83}$. However, the relationship between SSS and $E-P$ is often complicated by upper-ocean dynamics by virtue of the salt conservation equation ${ }^{80,84}$. Even in regions that are dominated by heavy rainfall, such as the ITCZ across the entire tropical ocean, or regions dominated by strong evaporation, such as the subtropical evaporative regions, the change of SSS is controlled primarily by processes internal to the ocean such as advection and mixing. $\mathrm{Yu}^{84}$ pointed out that $E-P$ forces salinity anomalies but does not damp them, which is unlike surface heat flux that serves as both forcing and damping mechanisms for SST ${ }^{85}$. Salinity anomalies tend to be more persistent than SST, and are more strongly influenced by upper-ocean circulation and mixing ${ }^{86,87}$. The use of salinity observations as a direct proxy of $E-P$ needs to carefully consider the role of advection and mixing processes in the ocean.

\section{Understanding the changes of the subtropical SSS maxima}

The subtropical SSS maxima (hereafter SSS-max) ${ }^{88}$ are found to be especially valuable as a subject for studying the relationship between ocean salinity, ocean dynamics, and the global water cycle. The SSS-max areas are situated in the middle of the subtropical gyres (Figure 1b), which are well away from the influence of western or eastern boundary currents, or equatorial current systems such as the Equatorial Countercurrents or the Equatorial Undercurrent. They are located near the mean locations of the subtropical atmospheric high pressure zone, meaning weak winds ${ }^{89}$. Being local maxima in SSS, horizontal gradients are small and thus horizontal advection terms in the salt conservation equation are small too ${ }^{90}$. This leads to the fact that 
large-scale oceanic mean and eddy flows are weak and that the contribution of ocean dynamics to the salinity balance at the surface are small. Surface freshwater flux forcing, or $E-P$, has been found to be the major term in the upper-ocean salinity balance ${ }^{90-95}$. Changes in E-P can have a large impact on the shape, size, position and configuration of these SSS-max areas. In addition, the SSS-max are the source of the so-called "River of Salt" ${ }^{96,97}$, which is a high salinity tongue at the depth of 50-300 $\mathrm{m}$ and propagates equatorward with a distinct signature visible for a long distance into the interior ${ }^{98}$. This water mass is often called "Subtropical Underwater" (STUW) ${ }^{99}$ and is formed by subduction of the SSS-max in later winter.

Recent studies by Yu et al. ${ }^{100}$ and Liu et al. ${ }^{101}$ showed that the STUW in the North Atlantic could carry the information about how the surface forcing has been changing, as the STUW properties are determined by its last contact with the atmosphere in the formation region. Yu et al. 100 found that an increase in size of the SSS-max in the subtropical North Atlantic in the past 50 years ${ }^{22,23,25}$ was caused by a poleward expansion of the feature's center in association with the widening of the Hadley circulation ${ }^{59-61,102,103}$. As a result of the SSS-max expansion, the ventilation zone of the STUW (marked by the location of the 36.7 isohaline) has shifted northward, by roughly $0.35 \pm 0.12^{\circ}$ latitude over a 34-year period (1979-2012) period, and also expanded westward into the Sargasso Sea (Figures 6a-b). This led to an increase in the subduction at a rate of $0.29 \pm 0.07 \mathrm{~Sv}$ per decade and the subsequent increase in the thickness of the STUW, most pronounced on the northern and western edges of the high-saline core (Figures 6c-d). The companion paper by Liu et al. ${ }^{101}$ suggested that the decadal change in subduction associated with the expansion of the SSS-max appeared to be related to the Atlantic Multidecadal Oscillation (AMO), an indicator of decadal climate variability within the Atlantic basin. Thus, changes in the global water cycle related to decadal climate variability were translated into interior variability of the ocean.

The other area examined here is the South Pacific SSS-max (Figure 7), which has been the subject of two recent studies, Hasson et al. ${ }^{92}$ and Bingham et al. ${ }^{104}$. Both studies looked at interannual variability, and, in contrast to the $\mathrm{Yu}$ et al. ${ }^{100}$ study cited above, compared the shape and configuration of the SSS-maxima to the $E-P$ forcing. The mid-latitude South Pacific is different from the North Atlantic, mainly in the much broader extent. The South Pacific has no regular ITCZ, but does have the SPCZ ${ }^{105}$ extending to the southeast from the western boundary which confines the SSS-max to the eastern part of the basin ${ }^{88}$. The South Pacific SSS-max was shown in both studies to migrate interannually. It underwent significant migration during the 2011-2016 period (Figure 7a), about $10^{\circ}$ eastward and 2-3 $3^{\circ}$ northward (towards the equator). Hasson et al. (2013) noted similar migration, but in the opposite direction and at a slower rate, about $1 \frac{2}{2}$ the speed. At the same time, the SSS-max increased in area by nearly a factor of 2 , though this is not obvious from Figure $7 \mathrm{~b}$, and in salinity, by about 0.1 . Though this change seems much more rapid than that in the North Atlantic shown by Yu et al. ${ }^{100}$, it should be noted that this is interannual, as opposed to decadal, and the time scales are different. Melzer and Subrahmanyam ${ }^{106}$ studied the SSS-max in all ocean basins and found decadal variability similar in magnitude and extent to those shown in the studies highlighted here.

Bingham et al. ${ }^{104}$ looked at a number of possibly related factors that might have caused the shifting noted in Figure $7 \mathrm{~b}$, but could not definitively point to any one in particular. They did note no interannual changes in $E-P$ that might have been responsible, or changes in the 
configuration of the SPCZ. The most likely culprit was interannual changes in Ekman transport and Ekman pumping causing changes in the underlying subtropical gyre. Thus, in the case of the South Pacific, changes observed in SSS are associated with oceanic processes possibly forced by changing winds. A significant relationship was found between the area of the SSS-max and the Pacific Decadal Oscillation (PDO), which, like the AMO is an indicator of decadal variability within the Pacific basin. This illustrates the complex interplay between atmospheric forcing through $E-P$ and winds, ocean circulation and the global water cycle occurs on all climate timescales from seasonal to interannual to decadal and longer.

\section{Linking salinity to $E-P$}

Several modeling studies have shown that the processes responsible for amplification of the ocean salinity pattern are not as straightforward as a simple response to changes in the $E-P$ field as ocean warming and ice melt also play a role. Considering the changing $E-P$ field first, Skliris et al. ${ }^{26}$ carried out an assessment of multiple reanalysis and synthesis datasets (NCEP/NCAR, NCEP-DOE, 20CRv2, ERA-Interim, COREv2, OAFlux) but found it difficult to establish robust changes in $E-P$ (e.g. Figure 3 ). The most reliable evidence for change was found in the southern hemisphere subtropical gyres, particularly in the Southeast Pacific where precipitation rates are low and increasing evaporation is the dominant term leading to a strengthening of net $E-P$. Changes in Tropical precipitation showed a much greater degree of disparity between the different datasets available reflecting difficulties in robustly representing changes in the intense and localised rainfall in the relatively narrow tropical convergence zone.

Grist et al. ${ }^{107}$ further developed a reanalysis-based $E-P$ analysis using a Temperature-Salinity framework which reduces the complexity arising from spatial variability. They found three temperature-dependent E-P change regimes. At less than $10^{\circ} \mathrm{C}$, corresponding primarily to the Southern Ocean, the region of net precipitation becomes fresher. For temperatures greater than $27^{\circ} \mathrm{C}$, corresponding to the Tropics there is an increase in net precipitation and a shift of this region in T-S space towards lower salinities. In the mid-range $15-27^{\circ} \mathrm{C}$ corresponding to the subtropics increased net evaporation was observed consistent with Skliris et al. ${ }^{26}$. The observation-based results were found to be broadly consistent with changes in a $1 \%$ increase $\mathrm{CO} 2$ run of the HadGEM3 climate model although the model also experienced a general shift of the main $E-P$ cells in T-S space towards warmer temperatures. Overall, they found that 19792007 was a period of hydrological cycle intensification resulting in a broadening of the global ocean salinity distribution. They also noted that the broadening occurred mainly in the tropical /subtropical temperature range. In contrast, at lower temperatures the water mass distribution shifted to lower salinities rather than broadening to both lower and higher salinities consistent with ocean processes redistributing high temperature freshening to lower temperatures.

Amplification of ocean salinity and its causes have been the subject of renewed interest 79,83 following the development of a new method based on water mass transformation theory for determining the amount of change in the water cycle ${ }^{82}$. Skliris et al. ${ }^{79}$ employed this method to infer the water cycle change from observed variations in salinity using three global datasets covering the period 1950-2010 and spanning a range of depths. Earlier analysis using surface ocean salinity observations suggested that the global water cycle had amplified by $8 \pm 5 \%{ }^{\circ} \mathrm{C}^{-1}$ of 
global mean surface temperature rise over 1950-2000 ${ }^{77}$. This result was consistent with expectations $\left(7 \%{ }^{\circ} \mathrm{C}^{-1}\right)$ based on the increased capacity of air to hold water as it warms following the $\mathrm{CC}$ equation but inconsistent with results obtained from state-of the art climate models which had a values about a factor of 2 smaller. Zika et al. ${ }^{82}$ found a smaller value for the amplification of $3.0 \pm 1.3 \%{ }^{\circ} \mathrm{C}^{-1}$ using full depth rather than surface salinity observations resolving the earlier disagreement with climate models for which the corresponding value is $4.3 \pm 2.0 \%{ }^{\circ} \mathrm{C}^{-1}$.

Zika et al. ${ }^{83}$ addressed the problem of the stronger amplification of the sea surface salinity than the full-depth field. By employing a set of targeted experiments with different forcings using the NEMO (Nucleus for European Modelling of the Ocean) model at 1 degree resolution, they were able to show that ocean warming has a significant impact on the surface salinity pattern amplification in addition to the effects of changing surface freshwater flux arising from the strengthening water cycle. The warming acts to increase near-surface stratification, prolonging existing salinity contrasts and causing surface salinity patterns to amplify further. This process accounts for about half of the observed change in sea surface salinity with the changing water cycle impact and a minor contribution from ice mass loss explaining the rest.

The results of the Zika et al. ${ }^{83}$ model experiments are shown in Fig.8 (panels a-f will correspond to Fig.1 c-h from Ref. 83). The observed sea surface salinity change from the EN4 product is shown in panel a and exhibits the familiar pattern of salinification in the subtropical gyres and freshening in the Tropics (e.g. Figure 5). A qualitatively similar pattern (panel b) is obtained from the model experiments in which the water cycle is amplified at $1 \%$ per decade over 100 years. The results from the ice mass loss experiment (panel c.) show high latitude surface freshening at high latitudes and only minor changes towards the equator. A much stronger response is seen in the warming experiments, in which the air-sea heat flux is perturbed. The final two panels show that the surface salinity response to the different perturbations is approximately linear as a model experiment with all three perturbations combined (panel e) closely resembles the sum of the individual perturbation experiments (panel f).

Ongoing research is concerned with the potential influence of vertical salt fluxes on the ocean salinity distribution 108 and the explanation for basin scale / marginal sea ocean salinity anomalies ${ }^{109,110}$. Liu et al. ${ }^{108}$ use the ECCO ocean state estimate to explore vertical salt fluxes and find that in the upper ocean, the vertical salt flux can be similar in magnitude to the air-sea freshwater flux. Further research is needed to establish how robust these results are to the choice of ocean state estimate. Regional variations in ocean salinity have long been the subject of interest e.g. major freshening anomalies in the North Atlantic in the 1970s and 1990s ${ }^{8,111}$. Most recently a significant fresh anomaly has developed in the subpolar gyre of the North Atlantic since 2012 and its causes and relation to a co-located cold water anomaly ${ }^{112}$ are under investigation. In the Pacific, Li et al. ${ }^{110}$ find using Argo that increased salinity in the upper 200 $\mathrm{m}$ since 2005 is primarily due to a reduction in precipitation. Marginal seas provide an opportunity at regional scales to study the impact of the changing water cycle on salinity. For example, an analysis of Mediterranean Sea salinity trends from observations over 1993-2016 shows a rapid salinification of this basin in recent decades linked to intensification of net evaporation ${ }^{108}$. Subsequent work using water mass transformation theory applied to observations over a longer sixty-year timescale (1950-2010) also finds that increased evaporation plays a key 
role and that long-term salinification results from regional water cycle changes rather than variations in the salt transport at the Straits of Gibraltar ${ }^{113}$.

\section{Discussion and future perspective}

Significant advances have been made in documenting the evidence for the hydrological response to the global warming of recent decades and in estimating and understanding the rate of intensification in the freshwater entering and leaving the ocean surface. In particular, historical ocean salinity data in corroboration with climate model simulations demonstrated that the global patterns of SSS changes are consistent with the "dry-gets-drier and wet-getswetter" paradigm, and the evidence supports an intensifying global water cycle as a consequence of the increase in water vapor transport. Ocean salinity has emerged as a key indicator of the past changes in the ocean water cycle, shaping up our view of salinity as a Nature's rain gauge for the $E-P$ over $71 \%$ of the Earth surface.

Nevertheless, significant uncertainties still remain in the current estimates of $E, P$, and their balance over the global ocean and in the length of time series needed for assessing possible longterm trends related to climate warming. Maintaining and improving the space-based observing system is key to advancing research in this area. Improving the observational capabilities for global river discharges and freshwater exchanges at polar seas is also important. Balance of the freshwater budget using $E, P$, river runoffs provides a physical constraint to help quantify uncertainties in $E-P$, but none of the present data products, sourced from either satellite or latest atmospheric reanalyses, is able to achieve the balance. Thus, the homogeneity in time series and reliability for long-term trends need to be improved.

Given the sensitivity of salinity to freshwater transport in and out of the ocean and the increasingly expanded availability of accurate salinity measurements over the globe ${ }^{114-116}$, the use of ocean salinity observations to fingerprint the changes of the hydrological cycle stands as a logical and practical alternative. However, significant questions remain in the role of ocean dynamical processes in the relationship between SSS and the $E-P$ forcing. As shown by climate model experiments, the ocean warming and changes to the water cycle and salinity are closely entangled ${ }^{79,83}$. Our understanding of the impacts of the changing water cycle on ocean salinity must take into account other factors including ocean warming ${ }^{83}$, interbasin patterns of moisture convergence ${ }^{117}$, and the interactions between SSS and the interior ocean via mixing and subduction ${ }^{108}$. The latter requires further observations to extend the $2000 \mathrm{~m}$ depth limit currently imposed by Argo. Enhancement of the Argo array for deep oceans, polar oceans, and marginal seas is expected to improve our ability to use salinity to estimate the change in the water cycle.

The recent development of salinity remote sensing has greatly enhanced the capability to measure SSS, allowing the land-sea linkage of the integrated water cycle ${ }^{116}$. Ongoing and recent missions include the Soil Moisture and Ocean Salinity (SMOS) mission by the European Space Agency (2010-present) as well as the Aquarius mission (2011-2015) and Soil Moisture Active Passive (SMAP) mission (2015-present) by the National Aeronautics and Space Administration (NASA). Satellite observing systems such as the upcoming SWOT mission provide an exciting 


\section{Acknowledgments:}

LY acknowledges the funding support of NASA Ocean Salinity Science Team (OSST) activities through Grant 80NSSC18K1335, NASA Making Earth System Data Records for Use in Research Environments (MEaSUREs) Program Grant 80NSSC18M0079, and NOAA Ocean Observing and Monitoring Division (OOMD) Grant NA19OAR4320074. SJ acknowledges funding from the UK Natural Environment Research Council including projects CLASS and CLAW (Climate-Scale Analysis of Air and Water masses), NE/K012932/1. FB acknowledges support from NASA OSST through grant 80NSSC18K1322.

\section{Competing interests:}

The authors declare no competing financial interests. 


\section{References}

1. Baumgartner, A. \& E. Reichel. 1975. The World Water Balance. Elsevier, New York, 179 pp.

2. Trenberth, K.E., L. Smith, T. Qian et al. 2007. Estimates of the global water budget and its annual cycle using observational and model data. J. Hydrometeor 8:758-769.

3. Trenberth, K.E., J.T. Fasullo \& J. Mackaro. 2011. Atmospheric moisture transports from ocean to land and global energy flows in reanalyses. J. Climate 24:4907-4924.

4. Gimeno, L., A. Stohl, R.M. Trigo, et al. 2012. Oceanic and terrestrial sources of continental precipitation. Rev. Geophys. 50:RG4003.

5. Stohl A, C. Forster \& H. Sodemann. 2008. Remote sources of water vapor forming precipitation on the Norwegian west coast at $60^{\circ} \mathrm{N}$ : A tale of hurricanes and an atmospheric river. J. Geophys. Res. 113:D05102

6. Coelho, C.S., C. Oliveira, T. Ambrizzi, et al. 2015. The 2014 southeast Brazil Austral summer drought: Regional scale mechanisms and teleconnections. Clim. Dyn. 45:1-16.

7. Gimeno, L., F. Dominguez, R. Nieto, et al. 2016. Major mechanisms of atmospheric moisture transport and their role in extreme precipitation events. Annu. Rev. Environ. Resour. 41:117-141

8. Dickson, R.R., J. Meincke, S.-A. Malmberg, et al. 1988. The "Great Salinity Anomaly" in the North Atlantic, 1968-1982. Prog. Oceanogr. 20:103-151.

9. Schmitt, R.W. 1995. The ocean component of the global water cycle: US National Report to International Union of Geodesy and Geophysics, 1991-1994. Rev. Geophys. 33(Supplement):1,395-1,409.

10. Elliott, G.W. 1974. Precipitation Signatures in sea-surface-layer conditions during BOMEX. J. Phys. Oceanogr. 4:498-501.

11. Lagerloef, G., F.R. Colomb, D. Le Vine, et al. 2008. The Aquarius/SAC-D mission: Designed to meet the salinity remote-sensing challenge. Oceanography 20:68-81.

12. Allen M.R. \& W.J. Ingram. 2002. Constraints on future changes in climate and the hydrologic cycle. Nature 419:224-232

13. Held, I.M. \& B.J. Soden. 2006. Robust responses of the hydrological cycle to global warming. J Climate 19:5686-5699.

14. Folland, C. K., Y.D. Ding, D.J. Griggs, et al. 2001. Observed climate variability and change. In Climate Change 2001: The Scientific Basis. J. T. Houghton et al. Eds: 99181. New York: Cambridge Univ. Press.

15. Huntington, T.G. 2006. Evidence for intensification of the global water cycle: review and synthesis. J. Hydrol. 319:83-95.

16. Zhang, X., F. Zwiers, G. Hegerl, et al. 2007. Detection of human influence on twentiethcentury precipitation trends. Nature 448: 461-465.

17. Trenberth, K.E., J. Fasullo \& L. Smith. 2005. Trends and variability in column-integrated atmospheric water vapor. Clim. Dyn. 24:741-758

18. Gu, G., R.F. Adler, G. Huffman, et al. 2007. Tropical rainfall variability on interannual-tointerdecadal/longer-time scales derived from the GPCP monthly product. J Climate 20:4033-4046.

19. Allan, R.P. \& B.J. Soden. 2008. Atmospheric warming and the amplification of precipitation extremes. Science 321:481-1484.

20. Yu, L. 2007. Global variations in oceanic evaporation (1958-2005): The role of the changing wind speed. J. Climate 20:5376-5390. 
21. Zhang, Y., J. L. Peña-Arancibia, T. R. McVicar et al. 2016. Multi-decadal trends in global terrestrial evapotranspiration and its components. Sci. Rep. 6:19124.

22. Curry, R., R. Dickson \& I. Yashayaev. 2003. Ocean evidence of a change in the fresh water balance of the Atlantic over the past four decades. Nature 426:826-829.

23. Boyer, T.P., S. Levitus, J.I. Antonov, et al. 2005. Linear trends in salinity for the World Ocean, 1955-1998. Geophys. Res. Lett. 32:L01604.

24. Rosenheim, B.E., P.K. Swart, S.R. Thorrold, et al. 2005. Salinity change in the subtropical Atlantic: Secular increase and teleconnections to the North Atlantic Oscillation. Geophys. Res. Lett. 32:L02603.

25. Durack, P.J. \& S.E. Wijffels. 2010. Fifty-year trends in global ocean salinities and their relationship to broad-scale warming. J. Climate 23:4342-4362.

26. Skliris, N., R. Marsh, S.A. Josey, et al. 2014. Salinity changes in the World Ocean since 1950 in relation to changing surface freshwater fluxes. Clim. Dyn. 43:709-736.

27. Fairall, C.W., E.F. Bradley, J.E. Hare, et al. 2003. Bulk Parameterization of Air-Sea Fluxes: Updates and Verification for the COARE Algorithm. J. Climate 16:571-591.

28. Josey, S.A., S. Gulev \& L. Yu. 2013. Exchanges through the ocean surface. In Ocean Circulation and Climate: A 21st Century Perspective. 2nd Ed. G. Siedler, S. Griffies, J. Gould, \& J. Church Eds.:115-140. Oxford, GB: Academic Press.(International Geophysics, 103).

29. Yu, L. 2019. Global Air-Sea Fluxes of Heat, Fresh Water, and Momentum: Energy Budget Closure and Unanswered Questions. Annu. Rev. Mar. Sci. 11:227-248.

30. Adler, R.F., M.R. Sapiano, G.J. Huffman, et al. 2018. The Global Precipitation Climatology Project (GPCP) monthly analysis (new version 2.3) and a review of 2017 global precipitation. Atmosphere 9:138.

31. Hou, A.Y., R.K. Kakar, S. Neeck, et al. 2014. The Global Precipitation Measurement Mission. Bull. Amer. Meteor. Soc. 95:701-722.

32. Grodsky, S.A., G. Reverdin, J.A. Carton, et al. 2014. Year-to-year salinity changes in the Amazon plume: Contrasting 2011 and 2012 Aquarius/SACD and SMOS satellite data. Remote Sens. Environ. 140:14-22.

33. Dai, A. \& K.E. Trenberth. 2002. Estimates of freshwater discharge from continents: Latitudinal and seasonal variations. J. Hydrometeor. 3:660-687.

34. Schanze, J.J., R.W. Schmitt \& L. Yu. 2010. The global oceanic freshwater cycle: A bestestimate quantification. J. Mar. Res. 68:569-595.

35. Fu, L.L., D. Alsdorf, R. Morrow, et al. 2012. SWOT: The Surface Water and Ocean Topography Mission: wide-swath altimetric elevation on Earth. Pasadena, CA: Jet Propulsion Laboratory, National Aeronautics and Space Administration. http://hdl.handle.net/2014/41996.

36. Hollinger, J.P., J.L. Peirce \& G.A. Poe. 1990.SSM/I instrument evaluation. IEEE Trans. Geosci. Remote Sens. 28:781-790.

37. Sun, Q., C. Miao, Q. Duan, et al. 2018. A review of global precipitation data sets: Data sources, estimation, and intercomparisons. Rev. Geophys. 56:79-107.

38. Saha, S., S. Moorthi, H.L. Pan, et al. 2010. The NCEP climate forecast system reanalysis. Bull. Am. Meteorol. Soc. 91:1015-1058.

39. Dee, D.P., S.M. Uppala, A.J. Simmons, et al. 2011. The ERA-Interim reanalysis: Configuration and performance of the data assimilation system. Q. J. Roy. Meteor. Soc. 137:553-597. 
40. Rienecker, M.M., M.J. Suarez, R. Gelaro, et al. 2011. MERRA: NASA's modern-era retrospective analysis for research and applications. J. Climate 24:3624-3648.

41. Yu L. 2020. The second generation of the Objectively Analyzed air-sea Flux (OAFlux2) Climatology on Momentum, Heat, and Moisture. J. Climate To be submitted.

42. Copernicus Climate Change Service (C3S) 2017. ERA5: Fifth generation of ECMWF atmospheric reanalyses of the global climate. Copernicus Climate Change Service Climate Data Store (CDS). https://cds.climate.copernicus.eu/cdsapp\#!/home

43. Kobayashi, S., Y. Ota, Y. Harada, et al. 2015. The JRA-55 reanalysis: General specifications and basic characteristics. J. Meteorol. Soc. Jpn. 93:5-48.

44. Gelaro, R., W. McCarty, M.J. Suárez, et al. 2017. The modern-era retrospective analysis for research and applications, version 2 (MERRA-2). J. Climate 30:5419-5454.

45. Bingham, F.M., T. Suga \& K. Hanawa. 2002. The origin of waters observed along $137^{\circ}$ E. $J$. Geophys. Res. 107:3073.

46. Delcroix, T., S. Cravatte \& M.J. McPhaden. 2007. Decadal variations and trends in tropical Pacific sea surface salinity since 1970. J. Geophys. Res. 112:C03012.

47. Wong, A.P., N.L. Bindoff \& J.A. Church. 1999. Large-scale freshening of intermediate waters in the Pacific and Indian Oceans. Nature 400:440-443.

48. Hosoda, S., T. Suga, N. Shikama, et al. 2009. Global surface layer salinity change detected by Argo and its implication for hydrological cycle intensification. J. Oceanogr. 65:579-586.

49. Roemmich, D. \& J. Gilson. 2009. The 2004-2008 mean and annual cycle of temperature, salinity, and steric height in the global ocean from the Argo Program. Prog. Oceanogr. 82:81-100.

50. Ishii, M., M. Kimoto \& M. Kachi. 2003. Historical Ocean Subsurface Temperature Analysis with Error Estimates. Mon. Wea. Rev. 131:51-73.

51. Good, S.A., M.J. Martin \& N.A. Rayner. 2013. EN4: Quality controlled ocean temperature and salinity profiles and monthly objective analyses with uncertainty estimates. $J$. Geophys. Res. Oceans 118:6704-6716.

52. Droghei, R., B. Buongiorno Nardelli \& R. Santoleri. 2018. A new global sea surface salinity and density dataset from multivariate observations (1993-2016). Front. Mar. Sci. 5:84.

53. Dai, A. 2006. Precipitation characteristics in eighteen coupled climate models. J. Climate 19:4605-4630.

54. Trenberth, K.E. \& C.J. Guillemot. 1995. Evaluation of the global atmospheric moisture budget as seen from analyses. J. Climate 8:2255-2272.

55. Seager, R., M. Ting, I. Held, et al. 2007. Model projections of an imminent transition to a more arid climate in southwestern North America. Science 316:1181-1184.

56. Chou, C., J.D. Neelin, C.A. Chen, et al. 2009. Evaluating the "rich-get-richer" mechanism in tropical precipitation change under global warming. J. Climate 22:1982-2005.

57. Seager, R., N. Naik \& G.A. Vecchi. 2010. Thermodynamic and dynamic mechanisms for large-scale changes in the hydrological cycle in response to global warming. J. Climate. 23:4651-4668.

58. Sherwood, S.C., R. Roca, T.M. Weckwerth, et al. 2010. Tropospheric water vapor, convection, and climate. Rev. Geophys. 48:RG2001.

59. Lu, J., G.A. Vecchi \& T.J. Reichler. 2007. Expansion of the Hadley cell under global warming. Geophys. Res. Lett. 34:L06805. 
60. Scheff, J. \& D. Frierson. 2012. Twenty-first-century multimodel subtropical precipitation declines are mostly midlatitude shifts. J. Climate 25:4330-4347.

61. Seidel, D.J., Q. Fu, W.J. Randel, et al. 2007. Widening of the tropical belt in a changing climate. Nat. Geosci., 1:21-24.

62. Yin, J. 2005. A consistent poleward shift of the storm tracks in simulations of 21 st century climate. Geophys. Res. Lett. 32:L18701.

63. Boer, G. J. 1993. Climate change and the regulation of the surface moisture and energy budgets. Clim. Dyn. 8:225-239.

64. Arkin, P.A., T.M. Smith, M.R.P. Sapiano et al. 2010. The observed sensitivity of the global hydrological cycle to changes in surface temperature. Environ. Res. Lett. 5:035201.

65. Chadwick, R., I. Boutle \& G. Martin. 2013. Spatial patterns of precipitation change in CMIP5: why the rich do not get richer in the tropics. J. Climate 26:3803-3822.

66. Byrne, M.P. \& P.A. O'Gorman. 2015. The response of precipitation minus evapotranspiration to climate warming: Why the "wet-get-wetter, dry-get-drier" scaling does not hold over land. J. Climate 28:8078-8092.

67. Roderick, M.L., F. Sun, W.H. Lim, et al. 2014. A general framework for understanding the response of the water cycle to global warming over land and ocean. Hydrol. Earth Syst. Sci. 18:1575-1589.

68. Chung, E.S., B. Soden, B.J. Sohn, et al. 2014. Upper-tropospheric moistening in response to anthropogenic warming. Proc. Natl. Acad. Sci. 111:11,636-11,641.

69. Pierrehumbert, R.T. 2002. The hydrologic cycle in deep-time climate problems. Nature 419:191-198.

70. Trenberth, K.E. 2011. Changes in precipitation with climate change. Clim. Res. 47:123-138

71. O'Gorman, P.A., R.P. Allan, M.P. Byrne, et al. 2012. Energetic constraints on precipitation under climate change. Surv. Geophys. 33:585-608.

72. Yu, L. \& X. Jin. 2018. A regime-dependent retrieval algorithm for near-surface air temperature and specific humidity from multi-microwave sensors. Remote Sens. Environ. 215:199-216.

73. Hansen, J., R. Ruedy, M. Sato, et al. 2010. Global surface temperature change. Rev. Geophys. 48:RG4004

74. Lenssen, N., G. Schmidt, J. Hansen, et al. 2019. Improvements in the GISTEMP uncertainty model. J. Geophys. Res. Atmos. 124:12, 6307-6326

75. Yu, L., X. Jin, S.A. Josey, et al. 2017. The global ocean water cycle in atmospheric reanalysis, satellite, and ocean salinity. J. Climate 30:3829-3852.

76. Flato, G., J. Marotzke, B. Abiodun, et al. 2014. Chapter 9: Evaluation of climate models. In Climate change 2013: the physical science basis. Contribution of Working Group I to the Fifth Assessment Report of the Intergovernmental Panel on Climate Change:741866. New York: Cambridge Univ. Press.

77. Durack, P. J., S.E. Wijffels \& R.J. Matear. 2012. Ocean salinities reveal strong global water cycle intensification during 1950-2000. Science 336:455-458.

78. Helm, K.P., N.L. Bindoff \& J.A. Church. 2010. Changes in the global hydrological-cycle inferred from ocean salinity. Geophys. Res. Lett. 37:L18701.

79. Skliris, N., J.D. Zika, A.G. Nurser, et al. 2016. Global water cycle amplifying at half Clausius-Clapeyron rate. Sci. Rep. 6:38752. 
80. Vinogradova, N.T. \& R.M. Ponte. 2013. Clarifying the link between surface salinity and freshwater fluxes on monthly to interannual time scales. J. Geophys. Res. Oceans 118:3190-3201.

81. Vinogradova, N.T. \& P.M. Ponte. 2017. In search of fingerprints of the recent intensification of the ocean water cycle. J. Climate. 30:5513-5528.

82. Zika, J. D, N. Skliris, G. Nurser, et al. 2015. Maintenance and broadening of the ocean's salinity distribution by the water cycle. J. Climate 28:9550-9560.

83. Zika, J., N. Skliris, A.T. Blaker, et al. 2018. Improved estimates of water cycle change from ocean salinity: The key role of ocean warming. Environ. Res. Lett. 13:74036.

84. Yu, L. 2011. A global relationship between the ocean water cycle and near-surface salinity J. Geophys. Res. 116:C10025.

85. Frankignoul, C. 1985. Sea surface temperature anomalies, planetary waves and air-sea feedback in the middle latitudes. Rev. Geophys. 23:357-390.

86. Mignot, J. \& C. Frankignoul. 2003. On the interannual variability of surface salinity in the Atlantic. Clim. Dyn. 20:555- 565.

87. Mignot, J. \& C. Frankignoul. 2004. Interannual to interdecadal variability of sea surface salinity in the Atlantic and its link to the atmosphere in a coupled model. J. Geophys. Res. 109:C04005.

88. Gordon, A.L., C.F. Giulivi, J. Busecke, et al. 2015. Differences among subtropical surface salinity patterns. Oceanography 28:32-39.

89. D'Addezio, J.M. \& F.M. Bingham. 2014. A subtropical North Atlantic regional atmospheric moisture budget. J. Geophys. Res. Oceans 119:8731-8748.

90. Bryan, F. \& S. Bachman. 2015. Isohaline salinity budget of the North Atlantic salinity maximum. J. Phys. Oceanogr. 45:724-736.

91. Farrar, J.T., L. Rainville, A.J. Plueddemann, et al. 2015. Salinity and temperature balances at the SPURS central mooring during fall and winter. Oceanography 28:56-65.

92. Hasson, A., T. Delcroix \& J. Boutin. 2013. Formation and variability of the South Pacific sea surface salinity maximum in recent decades. J. Geophys. Res. Oceans 118:51095116.

93. Katsura, S., E. Oka, B. Qiu, et al. 2013. Formation and subduction of North Pacific Tropical Water and their interannual variability. J. Phys. Oceanogr. 43:2400- 2415.

94. Dohan, K., H.-Y. Kao \& G.S.E. Lagerloef. 2015. The freshwater balance over the North Atlantic SPUS domain from Aquarius satellite salinity, OSCAR satellite surface currents, and some simplified approaches. Oceanography 28:86-95.

95. Kolodziejczyk, N., G. Reverdin \& A. Lazar. 2015. Interannual variability of the mixed layer winter convection and spice injection in the eastern subtropical North Atlantic. $J$. Phys. Oceanogr. 45:504-525.

96. Qu, T., S. Gao \& I. Fukumori. 2011. What governs the North Atlantic salinity maximum in a global GCM? Geophys. Res. Lett. 38:L07602.

97. Schmitt, R.W. \& A. Blair. 2015. A river of salt. Oceanography, 28:40-45.

98. Kessler, W.S. 1999. Interannual variability of the subsurface high salinity tongue south of the equator at $165^{\circ}$ E. J Phys. Oceanogr. 29:2038- 2049.

99. O'Connor, B.M., R. Fine \& D. Olson. 2005. A global comparison of subtropical underwater formation rates. Deep-Sea Res. Part I. 52:1569-1590.

100. Yu, L., X. Jin \& H. Liu. 2018. Poleward shift in ventilation of the North Atlantic subtropical underwater. Geophys. Res. Lett. 45:258-266. 
101. Liu, H., L. Yu \& X. Lin. 2019. Recent decadal change in the North Atlantic Subtropical Underwater associated with the poleward expansion of the surface salinity maximum. $J$ Geophys. Res. Oceans 124:4433-4448.

102. Fu, Q., C.M. Johanson, J.M. Wallace, et al. 2006. Enhanced mid-latitude tropospheric warming in satellite measurements, Science 312:1179.

103. Hudson, R.D., M.F. Andrade, M.B. Follette, et al. 2006. The total ozone field separated into meteorological regimes - Part II: Northern Hemisphere mid-latitude total ozone trends. Atmos. Chem. Phys. 6:5183-5191.

104. Bingham, F. M., J.J.M. Busecke \& A.L. Gordon. 2019. Variability of the South Pacific subtropical surface salinity maximum. J. Geophys. Res. Oceans 124:6050-6066.

105. Linsley, B.K., A. Kaplan, Y. Gouriou, et al. 2006. Tracking the extent of the South Pacific Convergence Zone since the early 1600s. Geochem., Geophy., Geosy. 7:Q05003.

106. Melzer, B.A. \& B. Subrahmanyam. 2015. Investigating decadal changes in sea surface salinity in oceanic subtropical gyres. Geophys. Res. Lett. 42:7631-7638.

107. Grist, J. P., S.A. Josey, J.D. Zika, et al. 2016. Assessing recent air-sea freshwater flux changes using a surface temperature-salinity space framework. J. Geophys. Res. Oceans. 121:8787-8806.

108. Liu, C., X. Liang, R. Ponte, et al. 2019. Vertical redistribution of salt and layered changes in global ocean salinity. Nat. Commun. 10:3445.

109. Schroeder, K., J. Chiggiato, S.A. Josey, et al. 2017. Rapid response to climate change in a marginal sea. Sci. Rep. 7:4065.

110. Li, G., Y. Zhang, J. Xiao, et al. 2019. Examining the salinity change in the upper Pacific Ocean during the Argo period. Clim. Dyn. 53:6055-6074.

111. Josey, S.A. \& R. Marsh. 2005. Surface Freshwater Flux Variability and Recent Freshening of the North Atlantic in the Eastern Subpolar Gyre. J. Geophys. Res. 110: C05008.

112. Josey, S. A., J. J.-M. Hirschi, B. Sinha, et al. 2018. The recent Atlantic cold anomaly: Causes, consequences and related phenomena. Ann. Rev. Mar. Sci. 10:475-501.

113. Skliris, N., J. Zika, L. Herold, et al. 2018. Mediterranean sea water budget long-term trend inferred from salinity observations. Clim. Dyn. 51:2857-2876.

114. Reul, N., A.A Grodsky, M. Arias, et al. 2020. Sea surface salinity estimates from spaceborne L-band radiometers: an overview of the first decade of observation (20102019). Remote Sens. Environ. In press.

115. Boutin, J., Y. Chao, W.E. Asher, et al. 2016. Satellite and in situ salinity: Understanding near-surface stratification and subfootprint variability. Bull. Amer. Meteor. Soc. 97:1391-1407.

116. Vinogradova, N., T. Lee, J. Boutin, et al. 2019. Satellite salinity observing system: recent discoveries and the way forward. Front. Mar. Sci. 6:243.

117. Singh, H. K. A., A. Donohoe, C.M. Bitz, et al. 2016. Greater aerial moisture transport distances with warming amplify interbasin salinity contrasts. Geophys. Res.

Lett. 43:8677-8684.

118. Penny, S.G., S. Akella, S., M.A. Balmaseda, et al. 2019. Observational needs for improving ocean and coupled reanalysis, S2S prediction, and decadal prediction. Front. Mar. Sci. 6:391. 


\section{Figure legends}

Figure 1. (a) Mean evaporation-minus-precipitation (E-P) flux from OAFlux2 and GPCP. (b) Mean sea-surface salinity observed from SMAP. The period of 2016-2018 was used in constructing both mean fields.

Figure 2. Annual-mean time series of air temperature (Ta) at $2 \mathrm{~m}$ height (red) and sea surface temperature (Ts) (black).

Figure 3. Time series of $\mathrm{E}$ and $\mathrm{P}$, with linear trend estimates, derived from (a) OAFlux 2 and GPCP, (b) ERA5, (c) JRA55, and (d) MERRA2 for the 30-year period from 1988-2017. Corresponding E-P time series are shown in $(\mathrm{e})-(\mathrm{h})$ respectively.

Figure 4. Linear trends in E-P derived from (a) OAFlux2 and GPCP, (b) ERA5, (c) JRA55, and (d) MERRA2 for the 30-year period from 1988-2017. Reddish colors denote more evaporation and greenish colors denote more precipitation.

Figure 5. From Durack et al. 2010 (Figure 28.4). Three long-term estimates of global sea surface salinity (SSS) change after (a) Durack and Wijffels (2010; Analysis period 1950-2008), (b) Boyer et al. (2005; Analysis period 1955-1998), and (c) Hosoda et al. (2009; Analysis period 1975-2005) all scaled to represent equivalent magnitude changes over a 50-year period (PSS-78 50-year1). Black contours express the associated mean SSS for the analysis period. Broad-scale similarities exist between each independent estimate of long-term change, suggesting an increase in the spatial gradients of salinity have occurred over the observed record. However, regional scale differences are due to differing data sources and analysis methodologies.

Figure 6. Adapted from Yu et al. (2018). (a) Mean SSS in the subtropical North Atlantic in the 1980s (black contours) and the 2000s (magenta contours) with the SSS mean differences between the two decades in the background (colors). (b) The total shift in the positions of the selected isohalines located north of $25^{\circ} \mathrm{N}$, with error bars denoting the $95 \%$ confidence interval estimates. (c) The climatological mean thickness of the STUW. (d) The differences in mean STUW thickness between the 2000s and the 1980s.

Figure 7. Adapted from Bingham et al. (2019). (a) Mean SSS (2011-2015) in the eastern South Pacific with color values indicated at right. The thin black contour is 36.258 (see Gordon et al., 2015). Black dots are the latitude of maximum SSS for each longitude. The light dashed line is where the evolution of SSS over time is examined in (c). (b) Annual mean location of the 36.258 surface isohaline contour in the South Pacific. Year is indicated by the colors at the right. "*" symbols are the centroid of the feature shown for each year with the same color coding. (c) SSS from the EN4 data as a function of time from $25^{\circ} \mathrm{S}$ to $10^{\circ} \mathrm{S}$ along the light dashed line in (a). Color scale is at right.

Figure8. (a) Sea surface salinity from observational analysis using the EN4 dataset. b-f.) Model experiment stimulated sea surface salinity trend over 100 years in response to: (b) $1 \%$ per decade water cycle amplification; (c) idealised water flux anomaly from ice mass loss (water flux anomalies are applied in green boxes); (d) $0.2 \mathrm{Wm}^{-2}$ per decade surface heat flux anomaly; (e) combined water cycle amplification, heat flux and glacial mass loss forcing; and (f) sum of responses shown in (b)-(d). The colour scale for panel (c) has been reduced to amplify the small signal in that experiment. Figure adapted from Zika et al. (2018), (C) 2018 The Author(s). Published by IOP Publishing Ltd. CC BY. Used with permission. 
(a) $\quad$ E - P (OAFlux - GPCP)

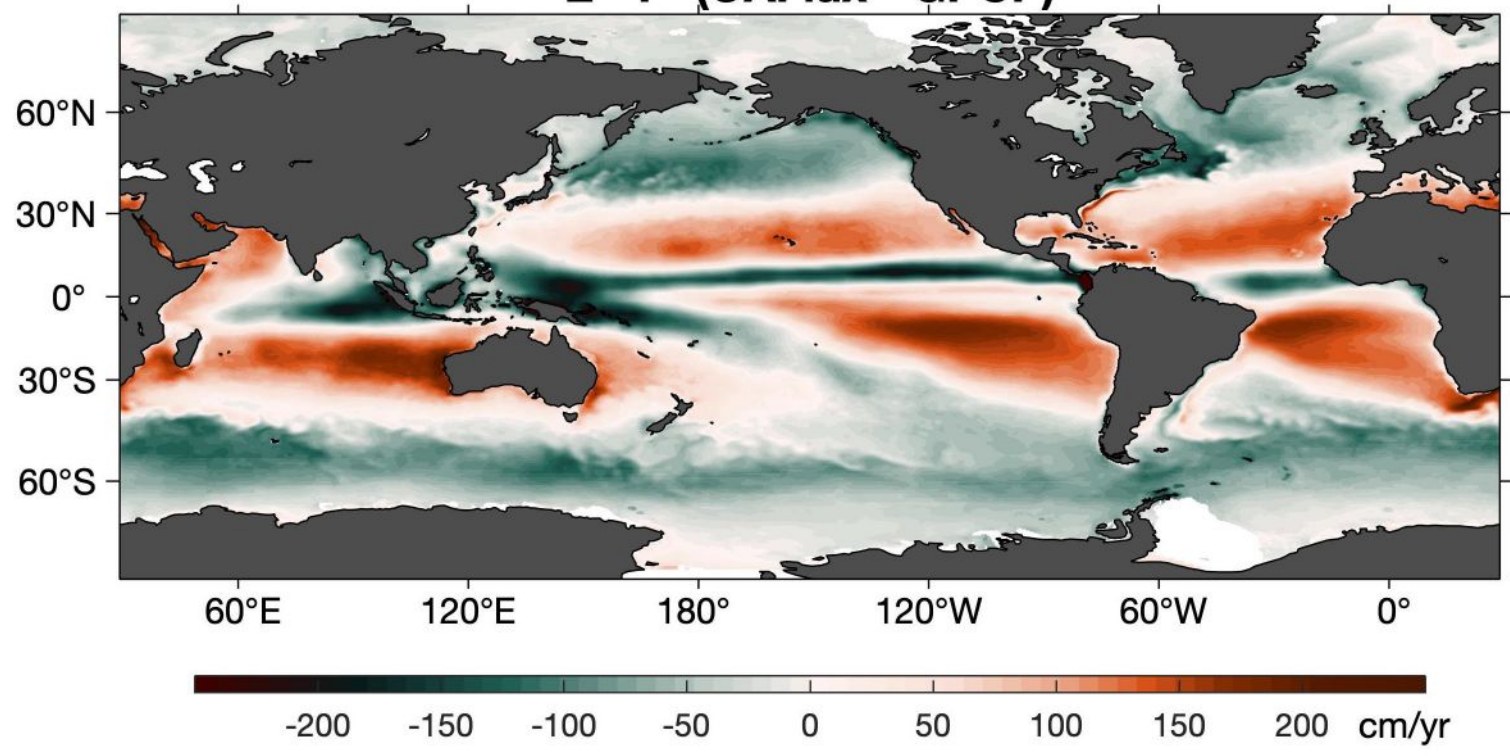

(b) Sea-Surface Salinity SMAP (CAPv4.2)

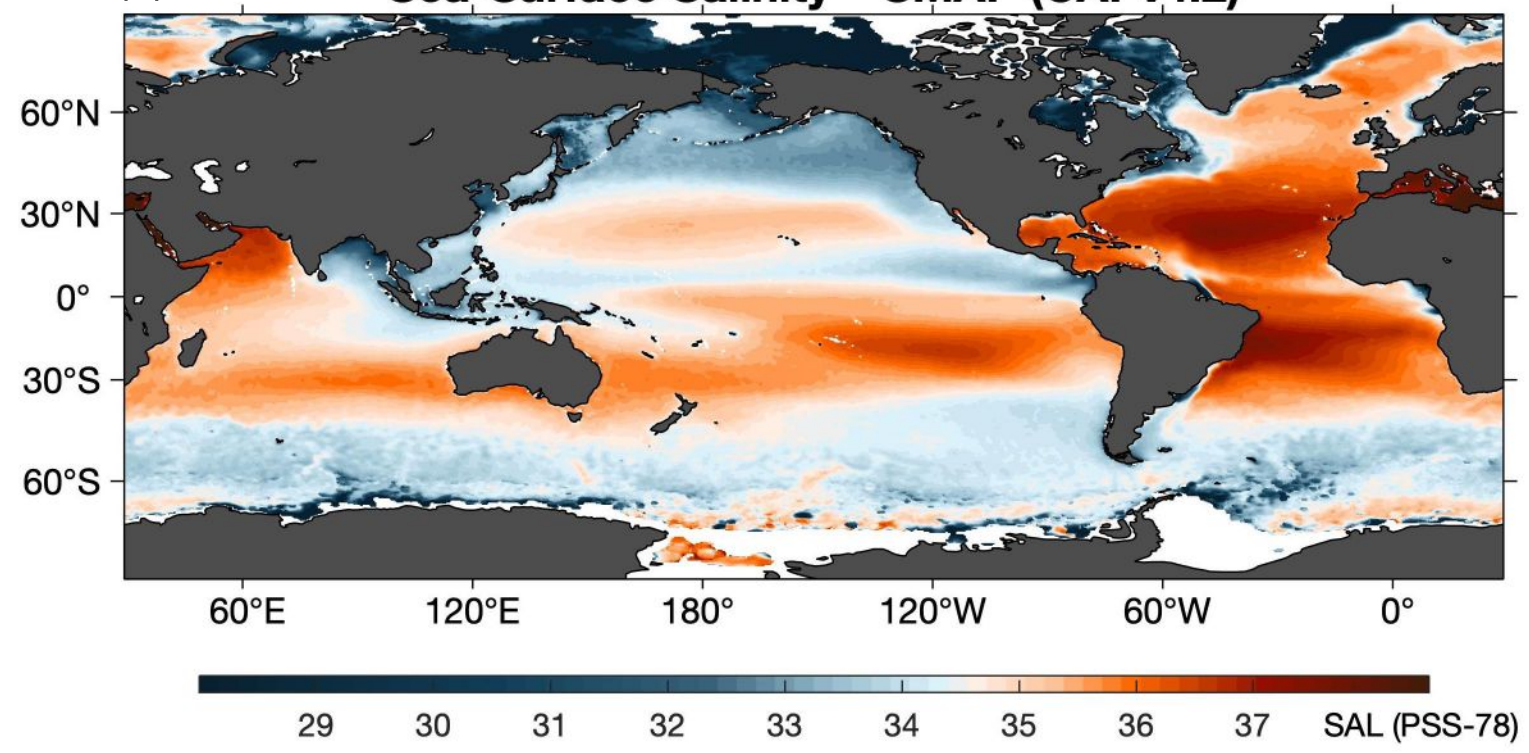

Figure 1. (a) Mean evaporation-minus-precipitation (E-P) flux from OAFlux2 and GPCP. (b) Mean sea-surface salinity observed from SMAP. The period of 2016-2018 was used in constructing both mean fields. 


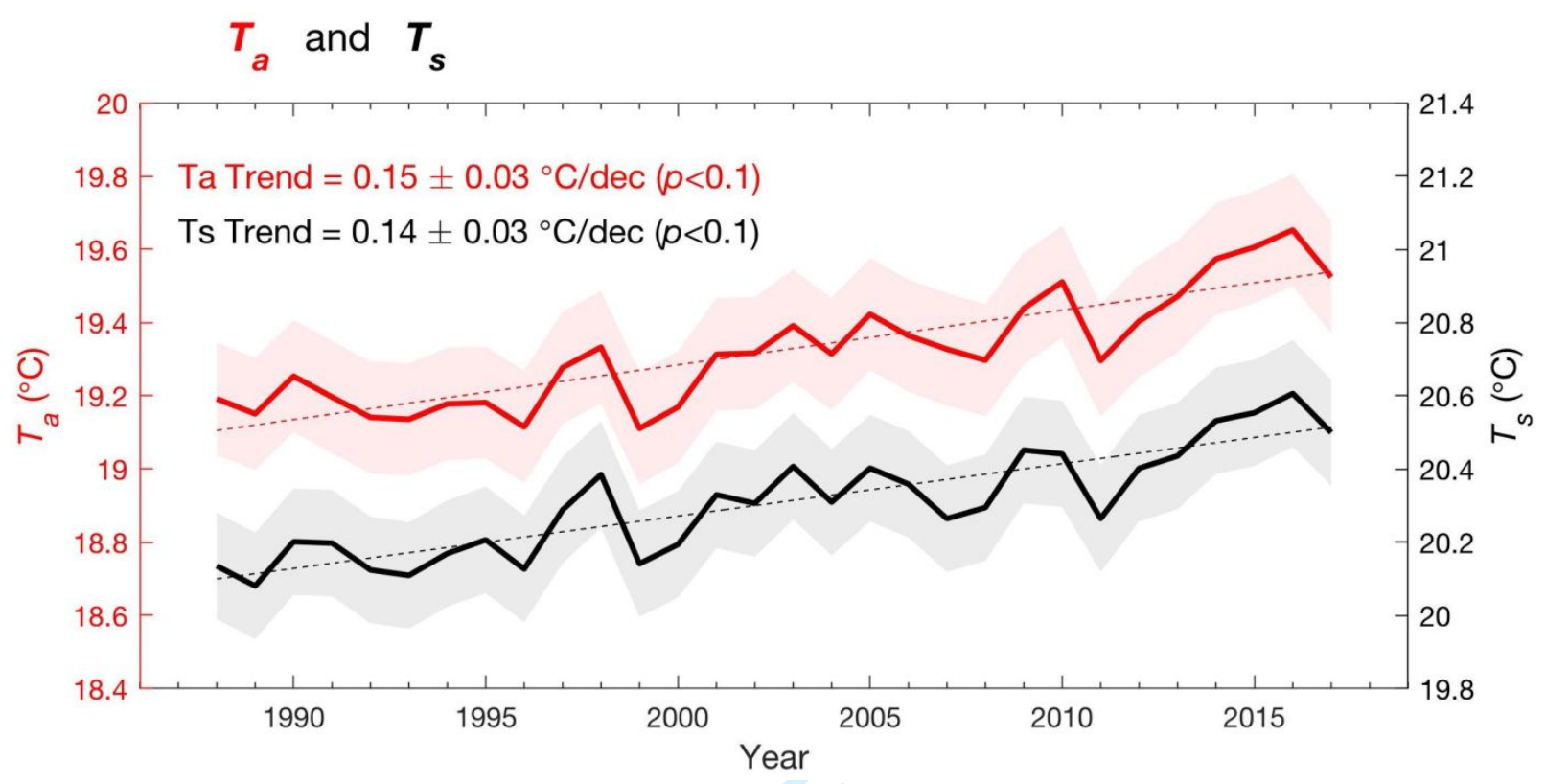

Figure 2. Annual-mean time series of air temperature (Ta) at $2 \mathrm{~m}$ height (red) and sea surface temperature (Ts) (black). 

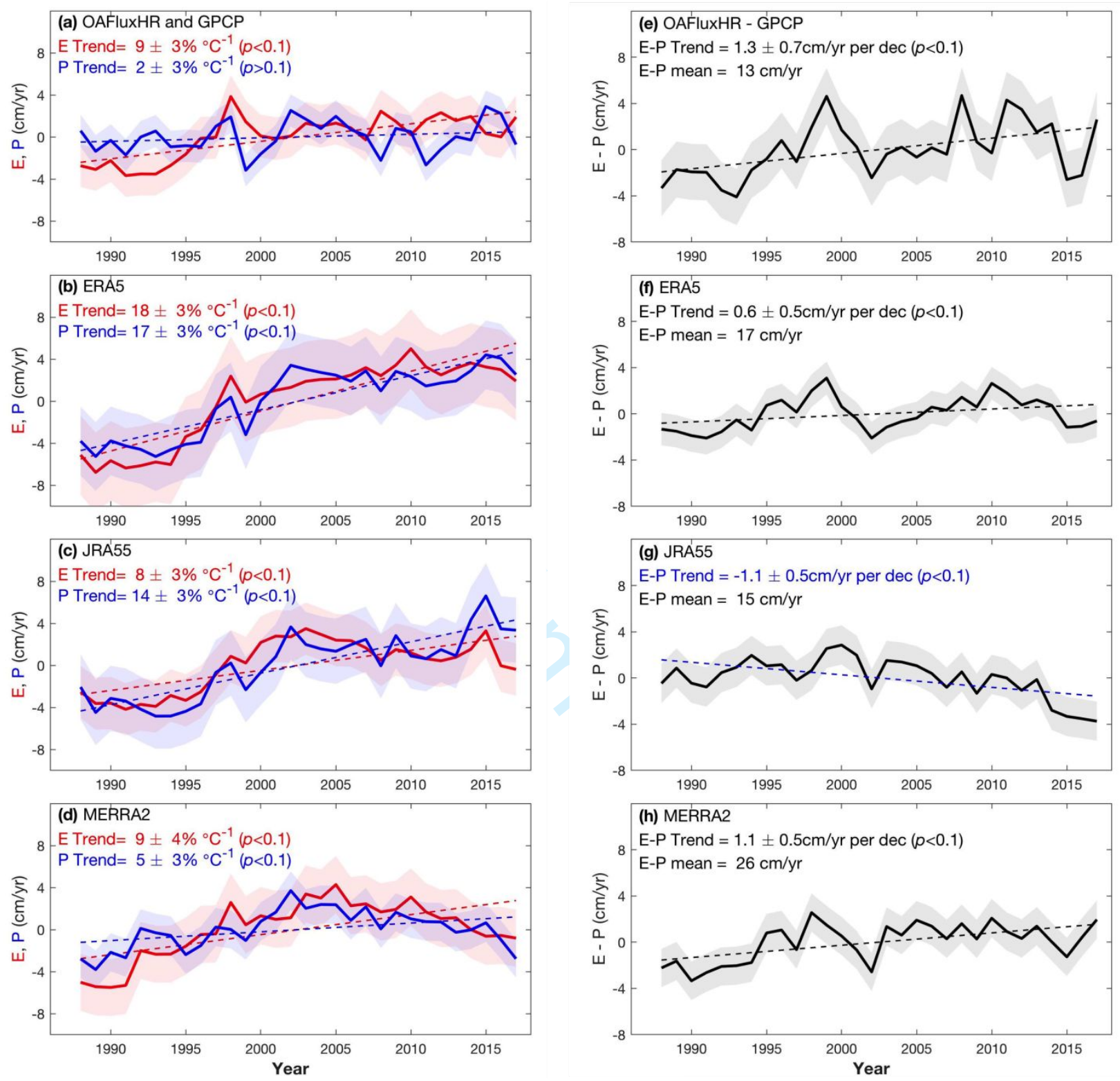

Figure 3. Time series of $E$ and $P$, with linear trend estimates, derived from (a) OAFlux2 and GPCP, (b) ERA5, (c) JRA55, and (d) MERRA2 for the 30-year period from 1988-2017. Corresponding E-P time series are shown in (e) - (h) respectively. 
(a) OAFluxHR - GPCP

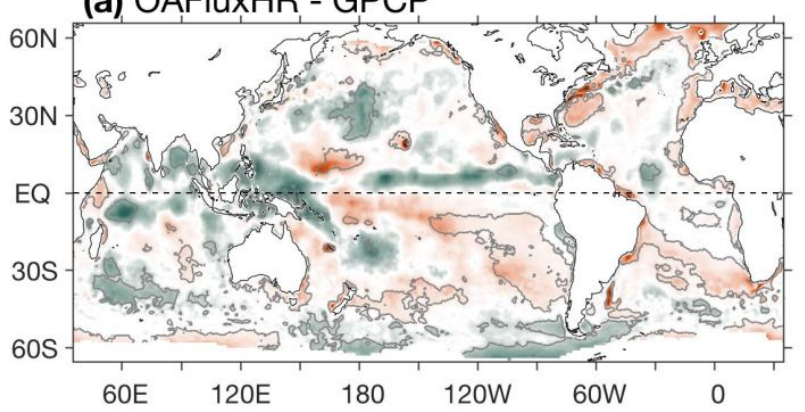

(c) JRA55

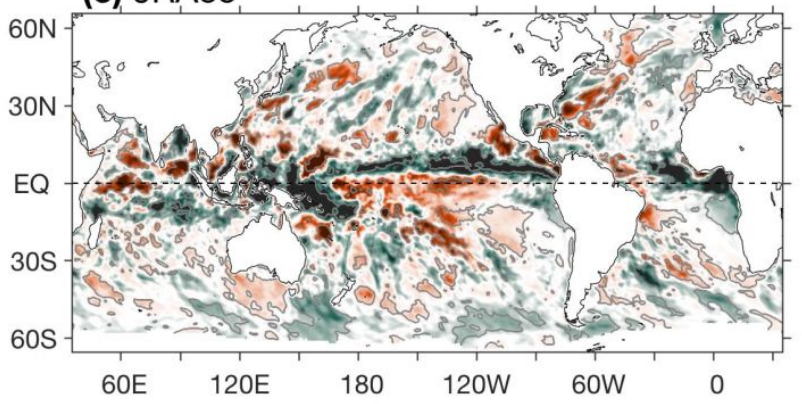

$-30$ (d) MERRA2

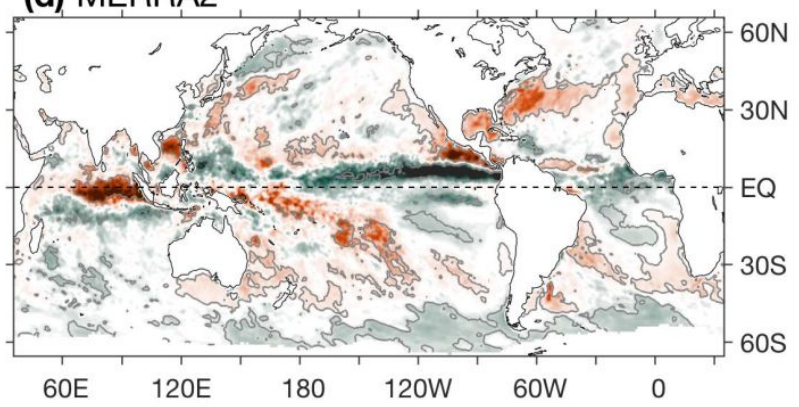

(b) ERA5

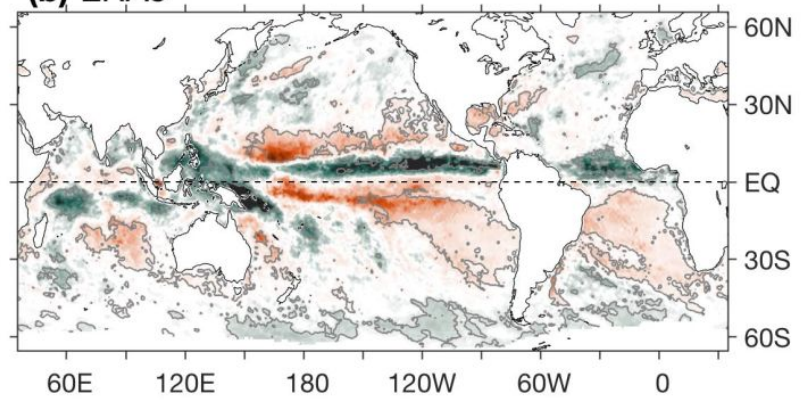

$\mathrm{cm} / \mathrm{yr}$ per dec

Figure 4. Linear trends in E-P derived from (a) OAFlux2 and GPCP, (b) ERA5, (c) JRA55, and (d) MERRA2 for the 30-year period from 1988-2017. Reddish colors denote more evaporation and greenish colors denote more precipitation. 


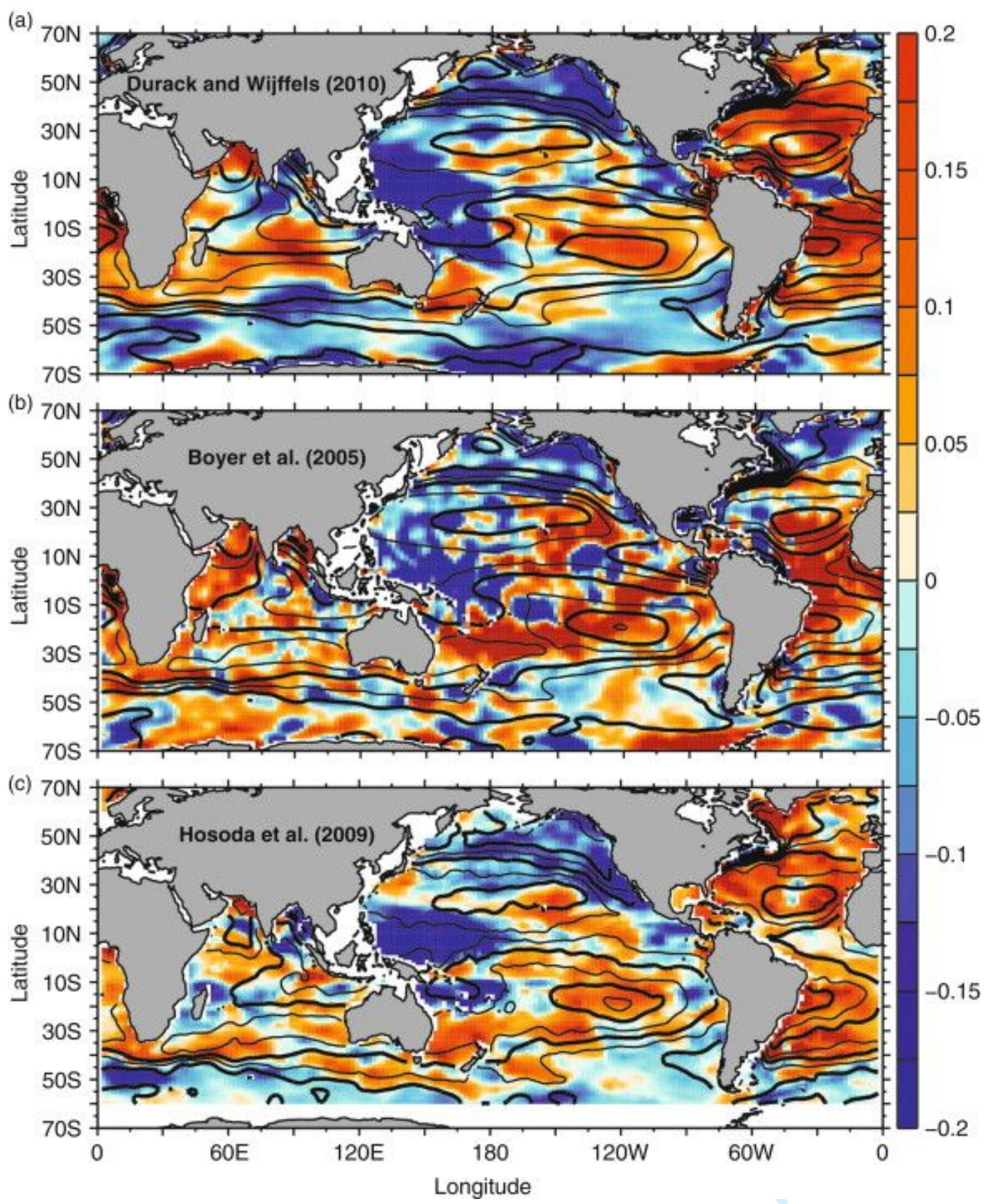

Figure 5. From Durack et al. 2010 (Figure 28.4). Three long-term estimates of global sea surface salinity (SSS) change after (a) Durack and Wijffels (2010; Analysis period 1950-2008), (b) Boyer et al. (2005; Analysis period 1955-1998), and (c) Hosoda et al. (2009; Analysis period 1975-2005) all scaled to represent equivalent magnitude changes over a 50-year period (PSS-78). Black contours express the associated mean SSS for the analysis period. Broad-scale similarities exist between each independent estimate of long-term change, suggesting an increase in the spatial gradients of salinity have occurred over the observed record. However, regional scale differences are due to differing data sources and analysis methodologies. 

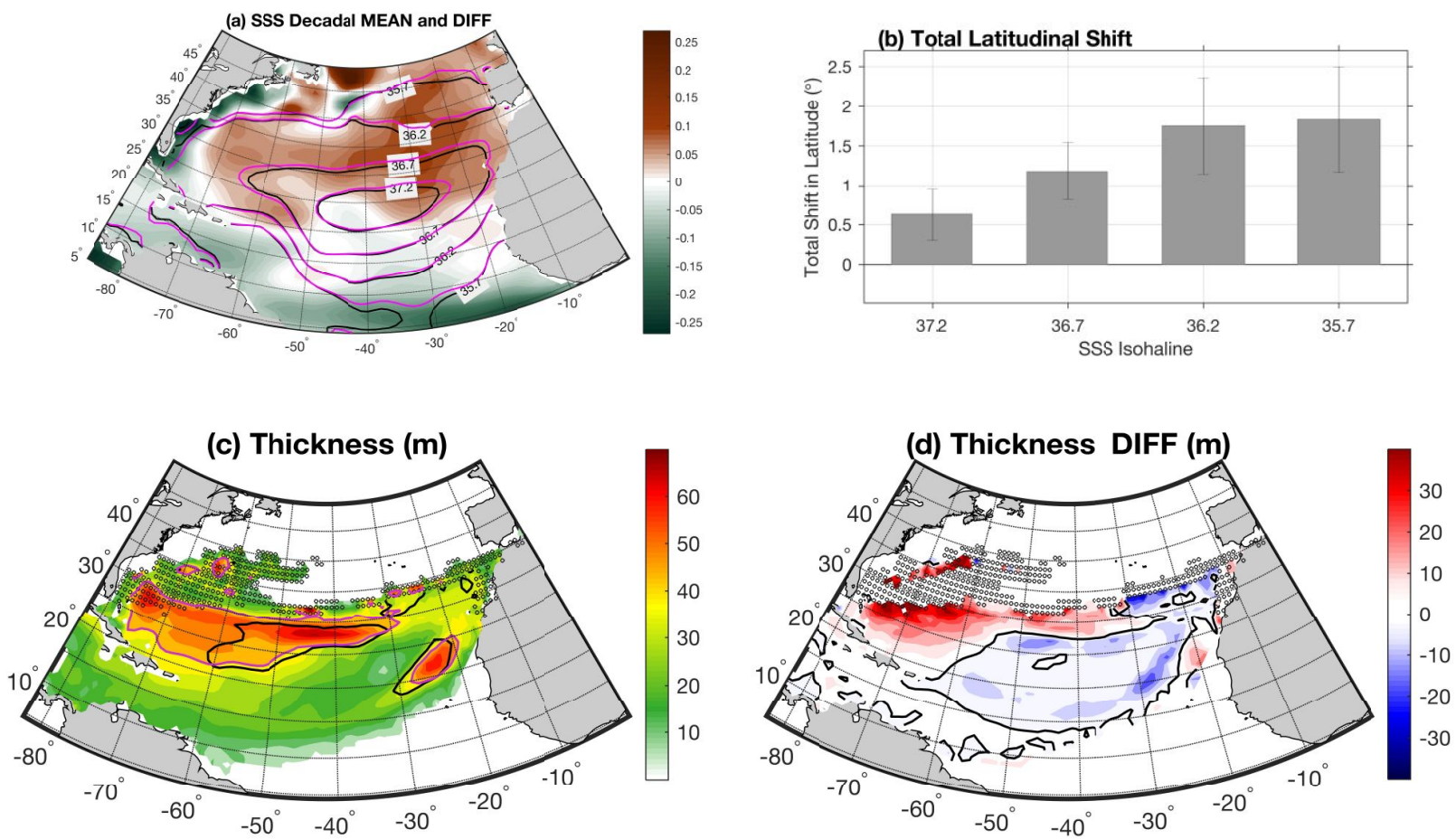

Figure 6. Adapted from Yu et al. (2018). (a) Mean SSS in the subtropical North Atlantic in the 1980s (black contours) and the 2000s (magenta contours) with the SSS mean differences between the two decades in the background (colors). (b) The total shift in the positions of the selected isohalines located north of $25^{\circ} \mathrm{N}$, with error bars denoting the $95 \%$ confidence interval estimates. (c) The climatological mean thickness of the STUW. (d) The differences in mean STUW thickness between the 2000s and the 1980s. 
Figure 7. Adapted from Bingham et al. (2019). (a) Mean SSS (2011-2015) in the eastern South Pacific with color values indicated at right. The thin black contour is 36.258 (see Gordon et al., 2015). Black dots are the latitude of maximum SSS for each longitude. The light dashed line is where the evolution of SSS over time is examined in (c). (b) Annual mean location of the 36.258 surface isohaline contour in the South Pacific. Year is indicated by the colors at the right. "**" symbols are the centroid of the feature shown for each year with the same color coding. (c) SSS from the EN4 data as a function of time from $25 \mathrm{~S}$ to $10 \mathrm{~S}$ along the light dashed line in (a). Color scale is at right.

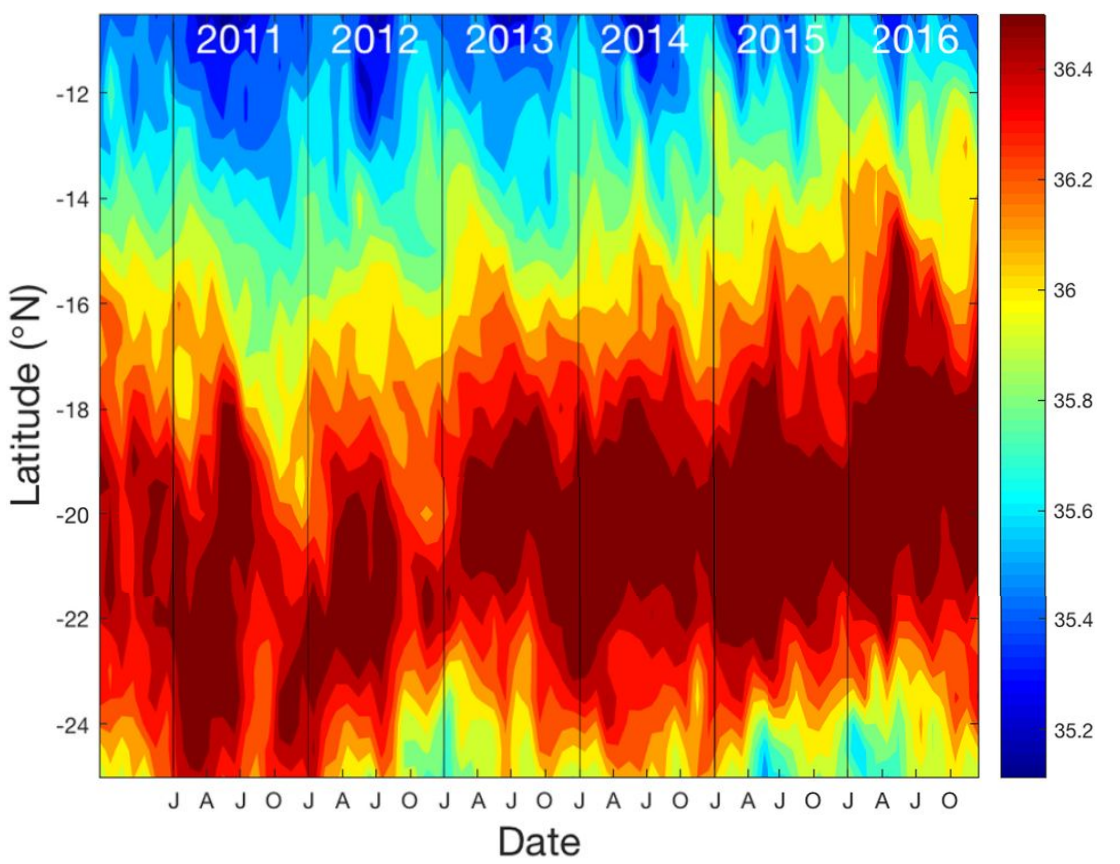


a) Observed surface salinity trend

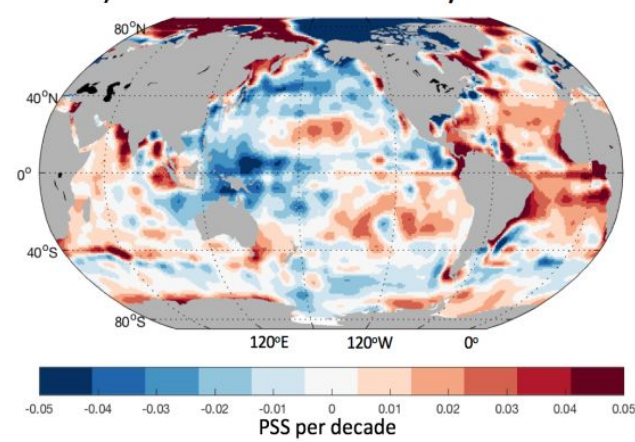

c) Response to idealised ice mass loss

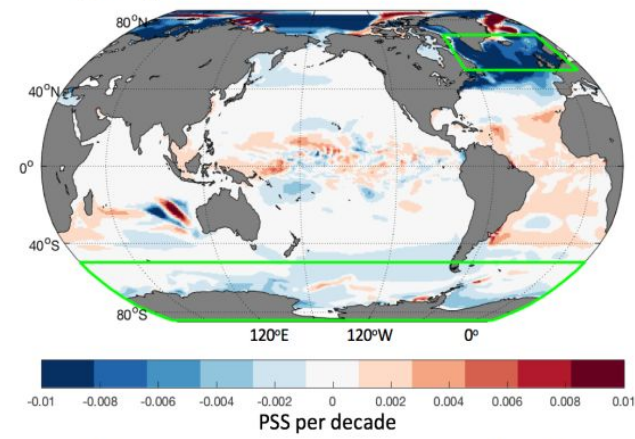

e) Response to all forcings combined

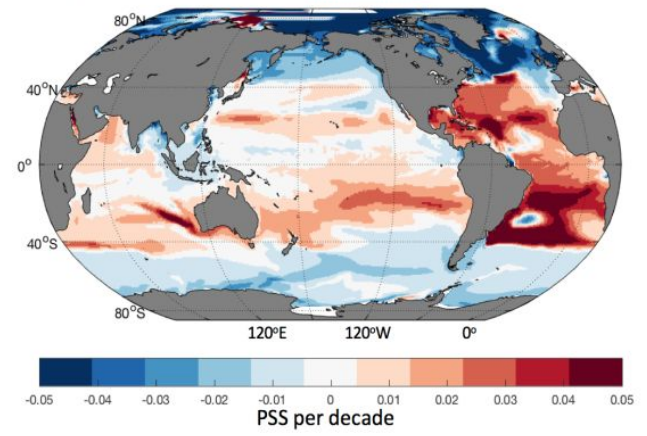

b) Response to water cycle amplification

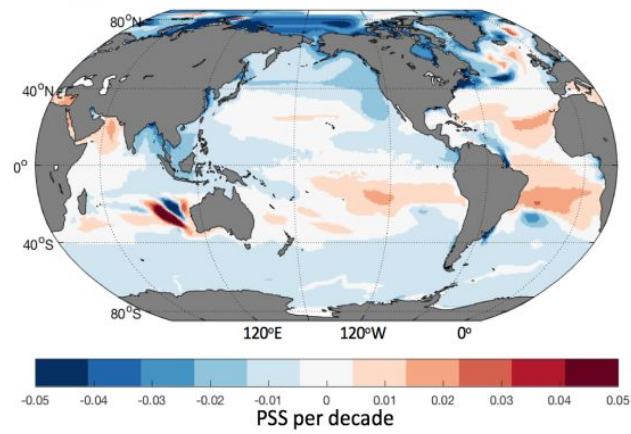

d) Response to surface heat flux

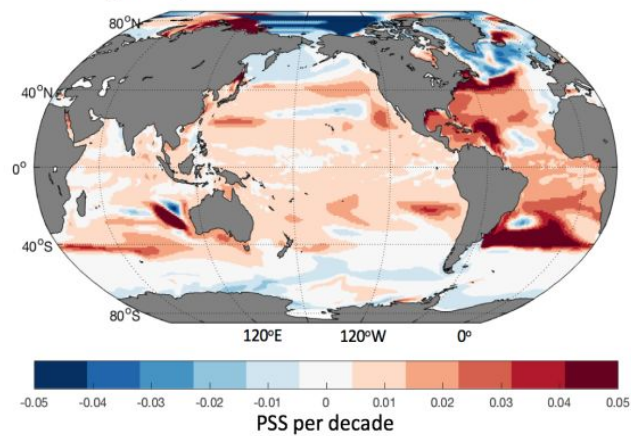

f) Sum of responses to each forcing

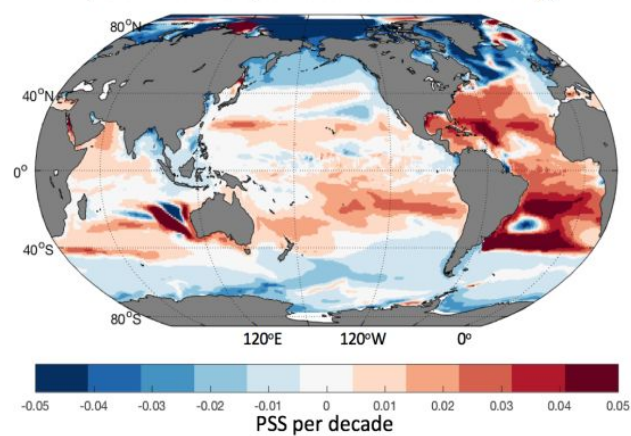

Figure8. (a) Sea surface salinity from observational analysis using the EN4 dataset. b-f.) Model experiment stimulated sea surface salinity trend over 100 years in response to: (b) 1\%per decade water cycle amplification; (c) idealised water flux anomaly from ice mass loss (water flux anomalies are applied in green boxes); (d) $0.2 \mathrm{Wm}^{-2}$ per decade surface heat flux anomaly; (e) combined water cycle amplification, heat flux and glacial mass loss forcing; and (f) sum of responses shown in (b)-(d). The colour scale for panel (c) has been reduced to amplify the small signal in that experiment. Figure adapted from Zika et al. (2018), (C) 2018 The Author(s). Published by IOP Publishing Ltd. CC BY. Used with permission. 

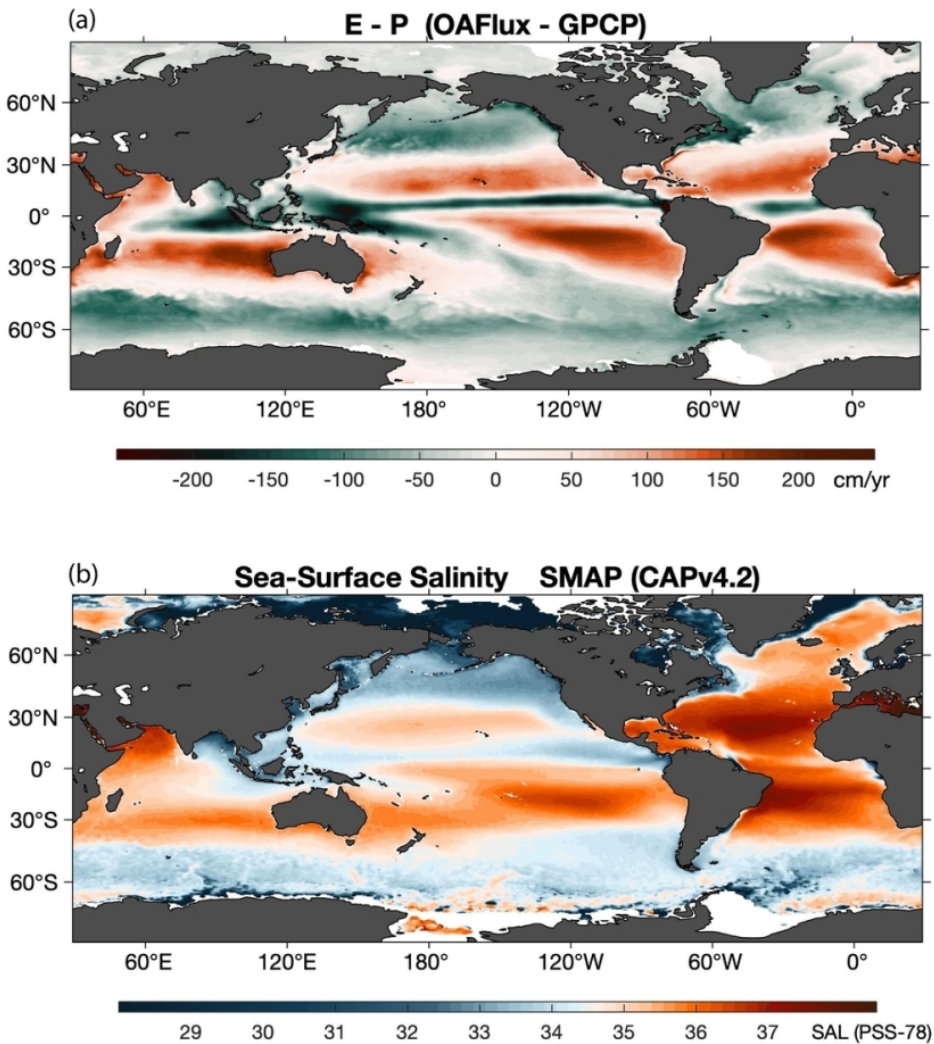

Figure 1. (a) Mean evaporation-minus-precipitation (E-P) flux from OAFlux2 and GPCP. (b) Mean seasurface salinity observed from SMAP. The period of 2016-2018 was used in constructing both mean fields.

$215 \times 279 \mathrm{~mm}(150 \times 150 \mathrm{DPI})$ 


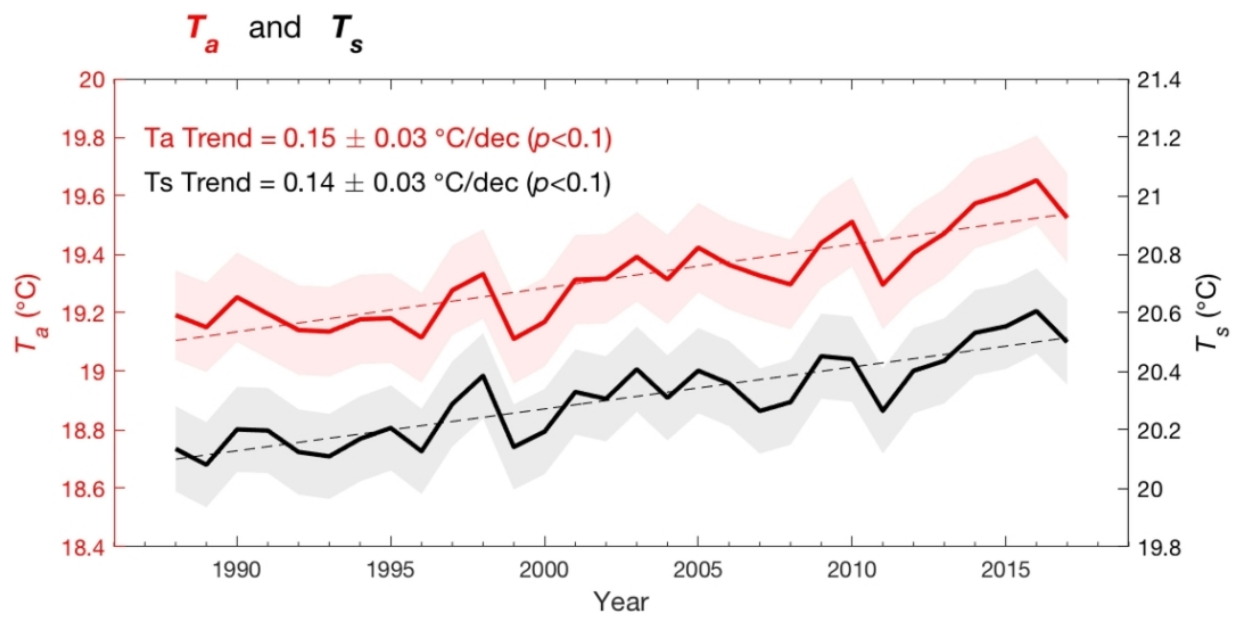

Figure 2. Annual-mean time series of air temperature (Ta) at $2 \mathrm{~m}$ height (red) and sea surface temperature (Ts) (black).

$203 \times 228 \mathrm{~mm}(150 \times 150 \mathrm{DPI})$ 

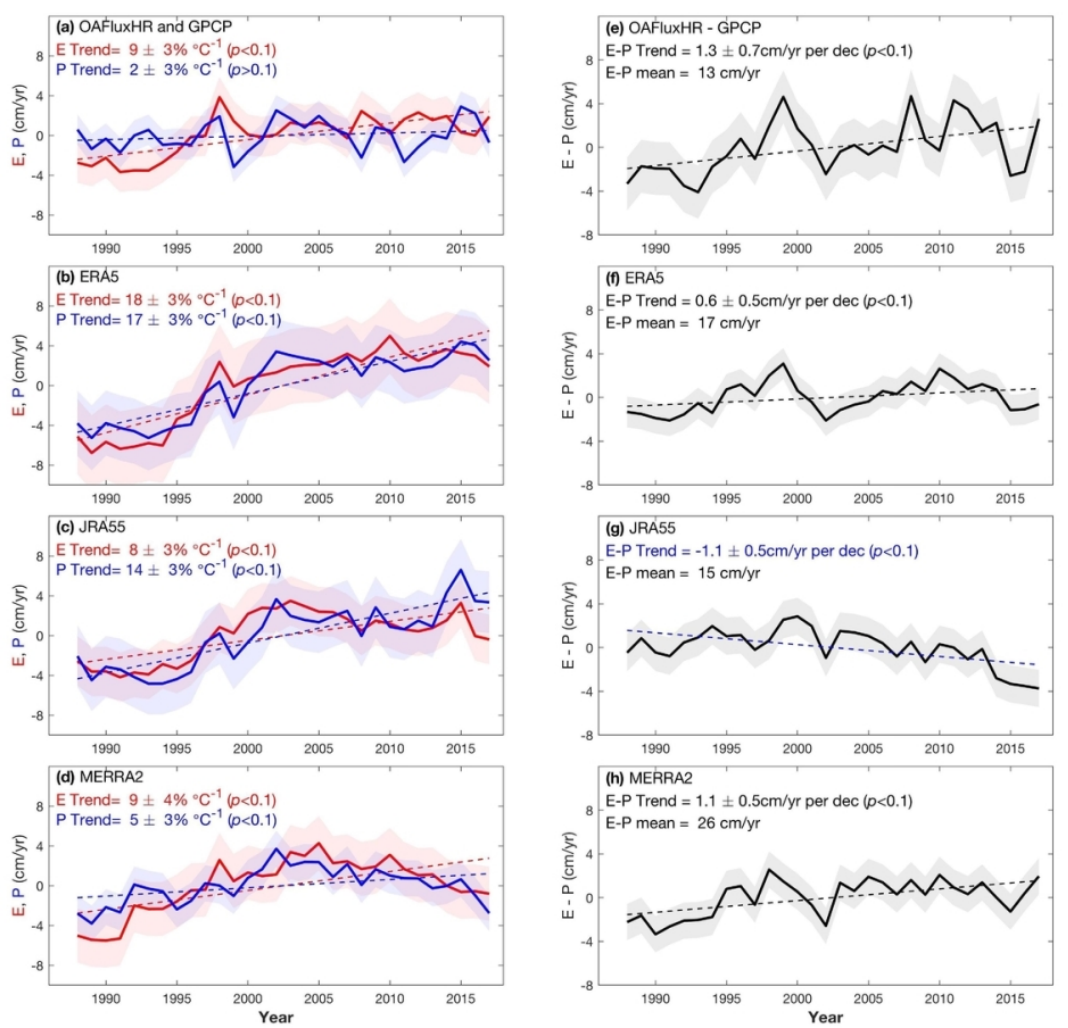

Figure 3. Time series of $E$ and $P$, with linear trend estimates, derived from (a) OAFlux2 and GPCP, (b) ERA5, (c) JRA55, and (d) MERRA2 for the 30-year period from 1988-2017. Corresponding E-P time series are shown in $(e)-(h)$ respectively.

$215 \times 279 \mathrm{~mm}(150 \times 150 \mathrm{DPI})$ 

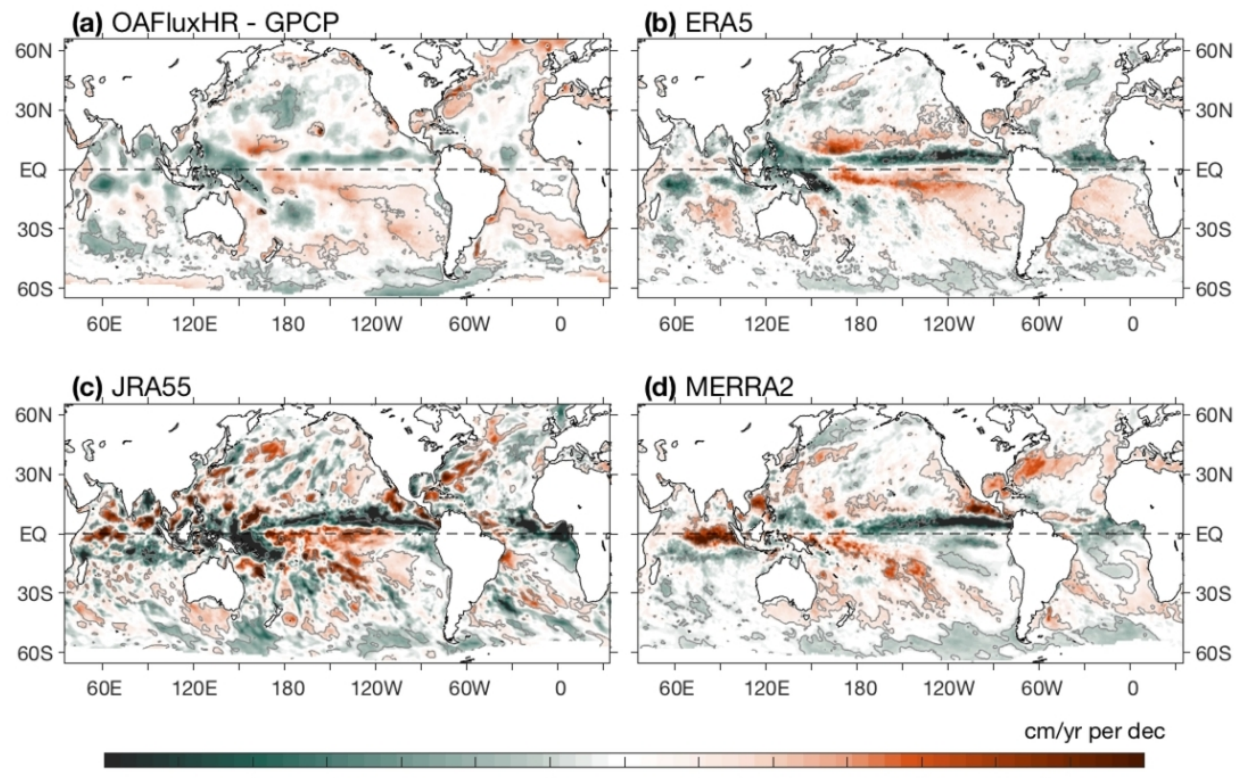

$\begin{array}{lllllllllllll}-30 & -25 & -20 & -15 & -10 & -5 & 0 & 5 & 10 & 15 & 20 & 25 & 30\end{array}$

Figure 4. Linear trends in E-P derived from (a) OAFlux2 and GPCP, (b) ERA5, (c) JRA55, and (d) MERRA2 for the 30-year period from 1988-2017. Reddish colors denote more evaporation and greenish colors denote more precipitation.

$203 \times 203 \mathrm{~mm}(150 \times 150 \mathrm{DPI})$ 


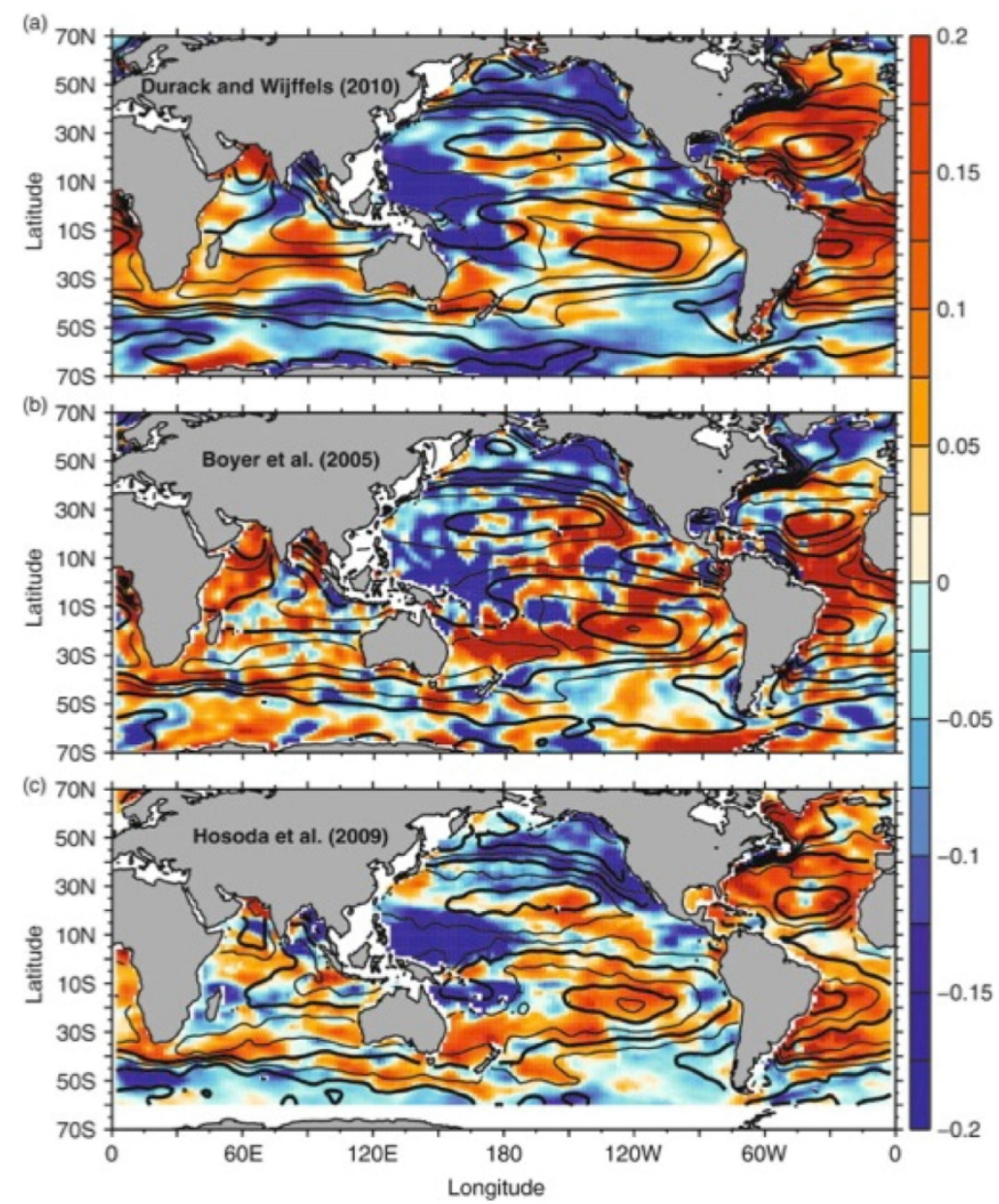

Figure 5. From Durack et al. 2010 (Figure 28.4). Three long-term estimates of global sea surface salinity (SSS) change after (a) Durack and Wijffels (2010; Analysis period 1950-2008), (b) Boyer et al. (2005;

Analysis period 1955-1998), and (c) Hosoda et al. (2009; Analysis period 1975-2005) all scaled to represent equivalent magnitude changes over a 50-year period (PSS-78 50-year1). Black contours express the associated mean SSS for the analysis period. Broad-scale similarities exist between each independent estimate of long-term change, suggesting an increase in the spatial gradients of salinity have occurred over the observed record. However, regional scale differences are due to differing data sources and analysis methodologies. 
Figure 6. Adapted from Yu et al. (2018). (a) Mean SSS in the subtropical North Atlantic in the 1980s (black contours) and the 2000s (magenta contours) with the SSS mean differences between the two decades in the background (colors). (b) The total shift in the positions of the selected isohalines located north of $25^{\circ} \mathrm{N}$, with error bars denoting the $95 \%$ confidence interval estimates. (c) The climatological mean thickness of the STUW. (d) The differences in mean STUW thickness between the 2000s and the 1980s.

$$
215 \times 279 \mathrm{~mm}(150 \times 150 \mathrm{DPI})
$$


Figure 7. Adapted from Bingham et al. (2019). (a) Mean SSS (2011-2015) in the eastern South Pacific with color values indicated at right. The thin black contour is 36.258 (see Gordon et al., 2015). Black dots are the latitude of maximum SSS for each longitude. The light dashed line is where the evolution of SSS over time is examined in (c). (b) Annual mean location of the 36.258 surface isohaline contour in the South Pacific. Year is indicated by the colors at the right. "*" symbols are the centroid of the feature shown for each year with the same color coding. (c) SSS from the EN4 data as a function of time from $25^{\circ} \mathrm{S}$ to $10^{\circ} \mathrm{S}$ along the light dashed line in (a). Color scale is at right.

\section{$215 \times 279 \mathrm{~mm}(150 \times 150 \mathrm{DPI})$}



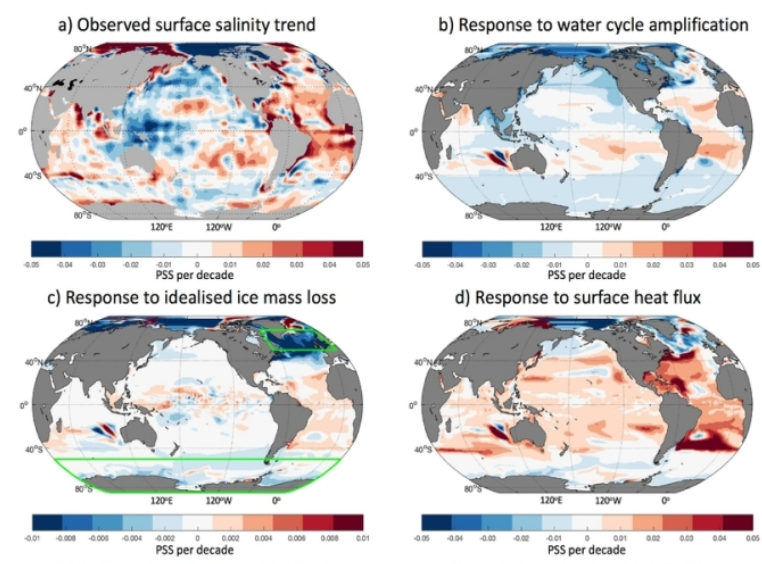

e) Response to all forcings combined

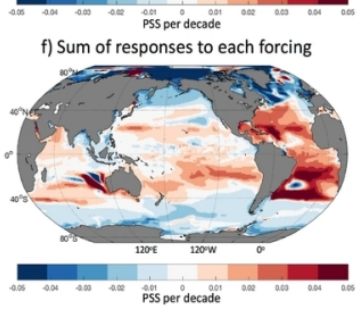

Figure8. (a) Sea surface salinity from observational analysis using the EN4 dataset. b-f.) Model experiment stimulated sea surface salinity trend over 100 years in response to: (b) $1 \%$ per decade water cycle amplification; (c) idealised water flux anomaly from ice mass loss (water flux anomalies are applied in green boxes); (d) $0.2 \mathrm{Wm}-2$ per decade surface heat flux anomaly; (e) combined water cycle amplification, heat flux and glacial mass loss forcing; and (f) sum of responses shown in (b)-(d). The colour scale for panel (c) has been reduced to amplify the small signal in that experiment. Figure adapted from Zika et al. (2018), (C) 2018 The Author(s). Published by IOP Publishing Ltd. CC BY. Used with permission.

\section{$215 \times 279 \mathrm{~mm}(150 \times 150 \mathrm{DPI})$}

